\title{
Nonlinear parabolic problem with lower order terms in Musielak- Orlicz spaces
}

Mhamed Elmassoudi ${ }^{\top}$, Ahmed Aberqi ${ }^{2}$, Jaouad Bennouna ${ }^{1}$

${ }^{1}$ University of Fez, Faculty of Sciences Dhar El Mahraz, Department of Mathematics, B.P 1796 Atlas Fez, Morocco.

${ }^{2}$ University of Fez, National School of Applied Sciences Fez,Morocco.

A R T I C L E I N F O

Article history:

Received: 05 May, 2017

Accepted: 15 July, 2017

Online: 28 December, 2017

Keywords:

Musielak-Orlicz space Non-

linear Parabolic Problems

Entropy solution

Condition sign

Lower order term
A B S T R A C T

We prove an existence result of entropy solutions for the nonlinear parabolic problems: $\frac{\partial b(x, u)}{\partial t}+A(u)-\operatorname{div}(\Phi(x, t, u))+H(x, t, u, \nabla u)=f$, and $A(u)=-\operatorname{div}(a(x, t, u, \nabla u))$ is a Leary-Lions operator defined on the inhomogeneous Musielak-Orlicz space, the term $\Phi(x, t, u)$ is a Cratheodory function assumed to be continuous on $u$ and satisfy only the growth condition $\Phi(x, t, u) \leq c(x, t) \bar{M}^{-1} M\left(x, \alpha_{0} u\right)$, prescribed by Musielak-Orlicz functions $M$ and $\bar{M}$ which inhomogeneous and not satisfy $\Delta_{2}$-condition, $H(x, t, u, \nabla u)$ is a Crathéodory function not satisfies neither the sign condition or coercivity and $f \in L^{1}\left(Q_{T}\right)$.

\section{Introduction}

Let $\Omega$ be a bounded open set of $\mathbb{R}^{N}(N \geq 2), T$ is a positive real number, and $Q_{T}=\Omega \times(0, T)$. Consider the following nonlinear Dirichlet equation:

$$
\left\{\begin{array}{l}
\frac{\partial b(x, u)}{\partial t}+A(u)-\operatorname{div}(\Phi(x, t, u))+H(x, t, u, \nabla u)=f \\
u(x, t)=0 \text { on } \partial \Omega \times(0, T) \\
b(x, u)(t=0)=b\left(x, u_{0}\right) \text { in } \Omega .
\end{array}\right.
$$

where $A(u)=-\operatorname{div}(a(x, t, u, \nabla u))$ is a Leary-Lions operator defined on the inhomogeneous Musielak-OrliczSobolev space $W_{0}^{1, x} L_{M}\left(Q_{T}\right), M$ is a Musielak-Orliczfunction related to the growths of the Carathéodory functions $a(x, t, u, \nabla u), \Phi(x, t, u)$ and $H(x, t, u, \nabla u)$ (see assumptions (12), (15) and (16). $b: \Omega \times \mathbb{R} \rightarrow \mathbb{R}$ is a Carathéodory function such that for every $x \in \Omega, b(x$, .) is a strictly increasing $\mathcal{C}^{1}(\mathbb{R})$-function, the data $f$ and $b\left(., u_{0}\right)$ in $L^{1}\left(Q_{T}\right)$ and $L^{1}(\Omega)$ respectively.

Starting with the prototype equation:

$$
\frac{\partial u}{\partial t}-\Delta_{p}(u)+\operatorname{div}\left(c(., t)|u|^{\gamma-1} u\right)+b|\nabla u|^{\delta}=f, \text { in } Q_{T} .
$$

In the Classical Sobolev-spaces, the authors in [1] have proved the existence of weak solutions, with $c(.,.) \equiv 0$. For $c(.,.) \in L^{2}\left(Q_{T}\right)$ and $p=2$, in [2] have proved the existence of entropy solutions, recently in [3] have proved an existence results of renormalized solutions in the case where $p \geq 2$ and $c(.,.) \in L^{r}\left(Q_{T}\right)$ with $r>\frac{N+p}{p-1}$, and by in [4] for more general parabolic term. For the elliptic version of the problem (1), more results are obtained see e.g. [5-7].

In the degenerate Sobolev-spaces an existence results is shown in [8] without sign condition in $H(x, t, u, \nabla u)$.

In the Orlicz-Sobolev spaces, the existence of entropy solutions of the problem (1) in [9] is proved where $H(x, t, u, \nabla u) \equiv 0$ and the growth of the first lower order $\Phi$ prescribed by an isotropic $\mathrm{N}$-function $P$ with $(P<<M)$. To our knowledge, differential equations in general MusielakSobolev spaces have been studied rarely see [10-14], then our aim in this paper is to overcome some difficulties encountered in these spaces and to generalize the result of $[4,9,15,16]$, and we prove an existence result of entropy solution for the obstacle parabolic problem (1), with less restrictive growth, and no coercivity condition in the first lower order term $\Phi$, and without sign condition in the second lower order $\mathrm{H}$, in the framework of inhomogeneous Orlicz-Sobolev spaces $W_{0}^{1, x} L_{M}\left(Q_{T}\right)$, and N-function $\mathrm{M}$, defining space does not satisfy the $\Delta_{2}$-condition.

This paper is organized as follows. In section 2, we recall some definitions, properties and technical lemmas about Musielak Orlicz Sobolev, In section 3 is devoted to specify the assumptions on $b, \Phi, f, u_{0}$,

${ }^{*}$ Corresponding Author: Mhamed Elmassoudi, Laboratoire LAMA , Fez, Morocco \& elmassoudi09@gmail.com 
giving the definition of a entropy solution of (1) and we establish the existence of such a solution Theorem 4 . In section 4, we give the proof of Theorem 4

\section{Musielak-Orlicz space and technical lemma}

In this part we will define the musielak-Orlicz function which control the growth of our operator.

\subsection{Musielak-Orlicz function}

Let $\Omega$ be an open subset of $\mathbb{R}^{N}(N \geq 2)$, and let $M$ be a real-valued function defined in $\Omega \times \mathbb{R}_{+}$and satisfying conditions:

$\left(\Phi_{1}\right): M(x,$.$) is an \mathrm{N}$-function for all $x \in \Omega$ (i.e. convex, non-decreasing, continuous, $M(x, 0)=0$,

$M(x, 0)>0$ for $t>0, \lim _{t \rightarrow 0} \sup _{x \in \Omega} \frac{M(x, t)}{t}=0$ and $\left.\lim _{t \rightarrow \infty} \inf _{x \in \Omega} \frac{M(x, t)}{t}=\infty\right)$.

$\left(\Phi_{2}\right): M(., t)$ is a measurable function for all $t \geq 0$.

A function $M$ which satisfies the conditions $\Phi_{1}$ and $\Phi_{2}$ is called a Musielak-Orlicz function. For a MusielakOrlicz function $M$ we put $M_{x}(t)=M(x, t)$ and we associate its non-negative reciprocal function $M_{x}^{-1}$, with respect to $t$, that is $M_{x}^{-1}(M(x, t))=M\left(x, M_{x}^{-1}(t)\right)=t$. Let $M$ and $P$ be two Musielak-Orlicz functions, we say that $P$ grows essentially less rapidly than $M$ at 0 (resp. near infinity, and we write $P<<M$, for every positive constant $c$, we have $\lim _{t \rightarrow 0}\left(\sup _{x \in \Omega} \frac{P(x, c t)}{M(x, t)}\right)=0$ $\left(\operatorname{resp} . \lim _{t \rightarrow \infty}\left(\sup _{x \in \Omega} \frac{P(x, c t)}{M(x, t)}\right)=0\right)$.

Remark 1 [12] If $P<<M$ near infinity, then $\forall \epsilon>0$ there exist $k(\epsilon)>0$ such that for almost all $x \in \Omega$ we have $P(x, t) \leq k(\epsilon) M(x, \epsilon t) \quad \forall t \geq 0$.

\subsection{Musielak-Orlicz space}

For a Musielak-Orlicz function $M$ and a mesurable function $u: \Omega \rightarrow \mathbb{R}$, we define the functionnal

$$
\rho_{M, \Omega}(u)=\int_{\Omega} M(x,|u(x)|) d x .
$$

The set $K_{M}(\Omega)=\{u: \Omega \rightarrow \mathbb{R}$ mesurable : $\left.\rho_{M, \Omega}(u)<\infty\right\}$ is called the Musielak-Orlicz class. The Musielak-Orlicz space $L_{M}(\Omega)$ is the vector space generated by $K_{M}(\Omega)$; that is, $L_{M}(\Omega)$ is the smallest linear space containing the set $K_{M}(\Omega)$. Equivalently

$$
L_{M}(\Omega)=\left\{u: \Omega \rightarrow \mathbb{R} \text { mesurable : } \rho_{M, \Omega}\left(\frac{u}{\lambda}\right)<\infty,\right.
$$

for some $\lambda>0\}$.

For any Musielak-Orlicz function $M$, we put $\bar{M}(x, s)=$ $\sup _{t \geq 0}(s t-M(x, s)) \cdot \bar{M}$ is called the Musielak-Orlicz function complementary to $M$ (or conjugate of $M$ ) in the sense of Young with respect to $s$. We say that a sequence of function $u_{n} \in L_{M}(\Omega)$ is modular convergent to $u \in L_{M}(\Omega)$ if there exists a constant $\lambda>0$ such that $\lim _{n \rightarrow \infty} \rho_{M, \Omega}\left(\frac{u_{n}-u}{\lambda}\right)=0$.
This implies convergence for $\sigma\left(\Pi L_{M}, \Pi L_{\bar{M}}\right)$ (see [17]). In the space $L_{M}(\Omega)$, we define the following two norms

$$
\|u\|_{M}=\inf \left\{\lambda>0: \int_{\Omega} M\left(x, \frac{|u(x)|}{\lambda}\right) d x \leq 1\right\},
$$

which is called the Luxemburg norm, and the so-called Orlicz norm by

$$
\|u\|_{M, \Omega}=\sup _{\|v\|_{M} \leq 1} \int_{\Omega}|u(x) v(x)| d x,
$$

where $\bar{M}$ is the Musielak-Orlicz function complementary to $M$. These two norms are equivalent [17]. $K_{M}(\Omega)$ is a convex subset of $L_{M}(\Omega)$. The closure in $L_{M}(\Omega)$ of the set of bounded measurable functions with compact support in $\bar{\Omega}$ is by denoted $E_{M}(\Omega)$. It is a separable space and $\left(E_{M}(\Omega)\right)^{*}=L_{M}(\Omega)$. We have $E_{M}(\Omega)=$ $K_{M}(\Omega)$, if and only if $M$ satisfies the $\Delta_{2}$-condition for large values of $t$ or for all values of $t$, according to whether $\Omega$ has finite measure or not.

We define

$$
\begin{array}{ll}
W^{1} L_{M}(\Omega)=\left\{u \in L_{M}(\Omega): D^{\alpha} u \in L_{M}(\Omega),\right. & \forall \alpha \leq 1\}, \\
W^{1} E_{M}(\Omega)=\left\{u \in E_{M}(\Omega): D^{\alpha} u \in E_{M}(\Omega),\right. & \forall \alpha \leq 1\},
\end{array}
$$

where $\alpha=\left(\alpha_{1}, \ldots, \alpha_{N}\right),|\alpha|=\left|\alpha_{1}\right|+\ldots+\left|\alpha_{N}\right|$ and $D^{\alpha} u$ denote the distributional derivatives. The space $W^{1} L_{M}(\Omega)$ is called the Musielak-Orlicz-Sobolev space. Let $\bar{\rho}_{M, \Omega}(u)=\sum_{|\alpha| \leq 1} \rho_{M, \Omega}\left(D^{\alpha} u\right)$ and $\|u\|_{M, \Omega}^{1}=\inf \{\lambda>$ $\left.0: \bar{\rho}_{M, \Omega}\left(\frac{u}{\lambda}\right) \leq 1\right\}$ for $u \in W^{1} L_{M}(\Omega)$.

These functionals are convex modular and a norm on $W^{1} L_{M}(\Omega)$, respectively. Then pair $\left(W^{1} L_{M}(\Omega),\|u\|_{M, \Omega}^{1}\right)$ is a Banach space if $M$ satisfies the following condition (see [10]),

There exists a constant $\quad c>0$ such that $\inf _{x \in \Omega} M(x, 1)>c$.

The space $W^{1} L_{M}(\Omega)$ is identified to a subspace of the product $\Pi_{\alpha \leq 1} L_{M}(\Omega)=\Pi L_{M}$. We denote by $\mathcal{D}(\Omega)$ the Schwartz space of infinitely smooth functions with compact support in $\Omega$ and by $\mathcal{D}(\bar{\Omega})$ the restriction of $\mathcal{D}(\mathbb{R})$ on $\Omega$. The space $W_{0}^{1} L_{M}(\Omega)$ is defined as the $\sigma\left(\Pi L_{M}, \Pi E_{\bar{M}}\right)$ closure of $\mathcal{D}(\Omega)$ in $W^{1} L_{M}(\Omega)$ and the space $W_{0}^{1} E_{M}(\Omega)$ as the(norm) closure of the Schwartz space $\mathcal{D}(\Omega)$ in $W^{1} L_{M}(\Omega)$.

For two complementary Musielak-Orlicz functions $M$ and $\bar{M}$, we have [17].

- The Young inequality:

$$
s t \leq M(x, s)+\bar{M}(x, t) \text { for all } s, t \geq 0, x \in \Omega .
$$

- The Holder inequality

$$
\begin{gathered}
\left|\int_{\Omega} u(x) v(x) d x\right| \leq\|u\|_{M, \Omega}\|v\|_{\bar{M}, \Omega} \text { for all } \\
u \in L_{M}(\Omega), v \in L_{\bar{M}}(\Omega) .
\end{gathered}
$$

We say that a sequence of functions $u_{n}$ converges to $u$ for the modular convergence in $W^{1} L_{M}(\Omega)$ (respectively in $W_{0}^{1} L_{M}(\Omega)$ ) if, for some $\lambda>0$.

$$
\lim _{n \rightarrow \infty} \bar{\rho}_{M, \Omega}\left(\frac{u_{n}-u}{\lambda}\right)=0 .
$$

The following spaces of distributions will also be used

$$
W^{-1} L_{\bar{M}}(\Omega)=\left\{f \in \mathcal{D}^{\prime}(\Omega): f=\sum_{\alpha \leq 1}(-1)^{\alpha} D^{\alpha} f_{\alpha}\right.
$$




$$
\text { where } \left.f_{\alpha} \in L_{\bar{M}}(\Omega)\right\} \text {, }
$$

and

$$
W^{-1} E_{\bar{M}}(\Omega)=\left\{f \in \mathcal{D}^{\prime}(\Omega): f=\sum_{\alpha \leq 1}(-1)^{\alpha} D^{\alpha} f_{\alpha}\right.
$$

where $\left.f_{\alpha} \in E_{\bar{M}}(\Omega)\right\}$.

Lemma 1 [17] Let $\Omega$ be a bounded Lipschitz domain in $\mathbb{R}^{N}$ and let $M$ and $\bar{M}$ be two complementary MusielakOrlicz functions which satisfy the following conditions:

- There exists a constant $c>0$ such that $\inf _{x \in \Omega} M(x, 1)>c$,

- There exists a constant $A>0$ such that for all $x, y \in \Omega$ with $|x-y| \leq \frac{1}{2}$, we have

$$
\frac{M(x, t)}{M(y, t)} \leq t^{\left(\frac{A}{\log \left(\frac{1}{|x-y|}\right)}\right)} \quad \text { for all } \quad t \geq 1,
$$

- For all $y \in \Omega, \int_{\Omega} M(y, 1) d x<\infty$,

- There exists a constant $C>0$ such that

$$
\bar{M}(y, t) \leq C \quad \text { a.e. } \quad \text { in } \Omega .
$$

Under this assumptions $\mathcal{D}(\Omega)$ is dense in $L_{M}(\Omega)$ with respect to the modular topology, $\mathcal{D}(\Omega)$ is dense in $W_{0}^{1} L_{M}(\Omega)$ for the modular convergence and $\mathcal{D}(\bar{\Omega})$ is dense in $W_{0}^{1} L_{M}(\Omega)$ for the modular convergence.

Consequently, the action of a distribution $S$ in in $W^{-1} L_{\bar{M}}(\Omega)$ on an element $u$ of $W_{0}^{1} L_{M}(\Omega)$ is well defined. It will be denoted by $\langle S, u\rangle$.

\subsection{Truncation Operator}

$T_{k}, k>0$, denotes the truncation function at level $k$ defined on $\mathbb{R}$ by $T_{k}(r)=\max (-k, \min (k, r))$. The following abstract lemmas will be applied to the truncation operators.

Lemma 2 [12] Let $F: \mathbb{R} \rightarrow \mathbb{R}$ be uniformly lipschitzian, with $F(0)=0$. Let $M$ be an Musielak-Orlicz function and let $u \in W_{0}^{1} L_{M}(\Omega)\left(\right.$ resp. $\left.u \in W^{1} E_{M}(\Omega)\right)$. Then $F(u) \in W^{1} L_{M}(\Omega)\left(\right.$ resp. $\left.u \in W_{0}^{1} E_{M}(\Omega)\right)$. Moreover, if the set of discontinuity points $D$ of $F^{\prime}$ is finite, then

$$
\frac{\partial}{\partial x_{i}} F(u)= \begin{cases}F^{\prime}(x) \frac{\partial u}{\partial x_{i}} & \text { a.e. in }\{x \in \Omega ; u(x) \notin D\} \\ 0 & \text { a.e. in }\{x \in \Omega ; u(x) \in D\}\end{cases}
$$

Lemma 3 Suppose that $\Omega$ satisfies the segement property and let $u \in W_{0}^{1} L_{M}(\Omega)$. Then, there exists a sequence $u_{n} \in \mathcal{D}(\Omega)$ such that $u_{n} \rightarrow u$ for modular convergence in $W_{0}^{1} L_{M}(\Omega)$. Furthermore, if $u \in W_{0}^{1} L_{M}(\Omega) \cap L^{\infty}(\Omega)$ then $\left\|u_{n}\right\|_{\infty} \leq(N+1)\|u\|_{\infty}$.
Let $\Omega$ be an open subset of $\mathbb{R}^{N}$ and let $M$ be a MusielakOrlicz function satisfying

$$
\int_{0}^{1} \frac{M_{x}^{-1}(t)}{t^{\frac{N+1}{N}}} d t=\infty \quad \text { a.e. } \quad x \in \Omega
$$

and the conditions of Lemma (1). We may assume without loss of generality that

$$
\int_{0}^{1} \frac{M_{x}^{-1}(t)}{t^{\frac{N+1}{N}}} d t<\infty \quad \text { a.e. } \quad x \in \Omega .
$$

Define a function $M^{*}: \Omega \times[0, \infty)$ by $M^{*}(x, s)=$ $\int_{0}^{s} \frac{M_{x}^{-1}(t)}{t^{\frac{N+1}{N}}} d t x \in \Omega$ and $s \in[0, \infty)$.

$M^{*}$ its called the Sobolev conjugate function of $M$ (see [18] for the case of Orlicz function).

Theorem 1 Let $\Omega$ be a bounded Lipschitz domain and let $M$ be a Musielak-Orlicz function satisfying (2), (3) and the conditions of lemma (1). Then $W_{0}^{1} L_{M}(\Omega) \hookrightarrow L_{M^{*}}(\Omega)$, where $M^{*}$ is the Sobolev conjugate function of $M$. Moreover, if $\Phi$ is any Musielak-Orlicz function increasing essentially more slowly than $M^{*}$ near infinity, then the imbedding $W_{0}^{1} L_{M}(\Omega) \hookrightarrow L_{\phi}(\Omega)$, is compact.

Corollaire 1 Under the same assumptions of theorem (1), we have $W_{0}^{1} L_{M}(\Omega) \hookrightarrow \hookrightarrow L_{M}(\Omega)$.

Lemma 4 If a sequence $u_{n} \in L_{M}(\Omega)$ converges a.e. to $u$ and if $u_{n}$ remains bounded in $L_{M}(\Omega)$, then $u \in L_{M}(\Omega)$ and $u_{n} \rightarrow u$ for $\sigma\left(L_{M}(\Omega), E_{\bar{M}}(\Omega)\right)$.

Lemma 5 Let $u_{n}, u \in L_{M}(\Omega)$. If $u_{n} \rightarrow u$ with respect to the modular convergence, then $u_{n} \rightarrow u$ for $\sigma\left(L_{M}(\Omega), L_{\bar{M}}(\Omega)\right)$.

Démonstration: Let $\lambda>0$ such that $\int_{\Omega} M\left(x, \frac{u_{n}-u}{\lambda}\right) d x \rightarrow$ 0 . Thus, for a subsequence, $u_{n} \rightarrow u$ a.e. in $\Omega$. Take $v \in L_{\bar{M}}(\Omega)$. Multiplying $v$ by a suitable constant, we can assume $\lambda v \in \mathcal{L}_{\bar{M}}(\Omega)$. By Young's inequality,

$$
\left|\left(u_{n}-u\right) v\right| \leq M\left(x, \frac{u_{n}-u}{\lambda}\right)+\bar{M}(x, \lambda v)
$$

which implies, by Vitali's theorem, that $\int_{\Omega} \mid\left(u_{n}-\right.$ $u) v \mid d x \rightarrow 0$.

\subsection{Inhomogeneous} Sobolev spaces

Musielak-Orlicz-

Let $\Omega$ an bounded open subset $\mathbb{R}^{N}$ and let $Q_{T}=$ $\Omega \times] 0, T$ [ with some given $T>0$. Let $M$ be an MusielakOrlicz function, for each $\alpha \in \mathbb{N}^{N}$, denote by $\nabla_{x}^{\alpha}$ the distributional derivative on $Q_{T}$ of order $\alpha$ with respect to the variable $x \in \mathbb{N}^{N}$. The inhomogeneous MusielakOrlicz-Sobolev spaces are defined as follows,

$$
\begin{aligned}
W^{1, x} L_{M}\left(Q_{T}\right) & =\left\{u \in L_{M}\left(Q_{T}\right): \nabla_{x}^{\alpha} u \in L_{M}\left(Q_{T}\right),\right. \\
& \left.\forall \alpha \in \mathbb{N}^{N},|\alpha| \leq 1\right\}, \\
W^{1, x} E_{M}\left(Q_{T}\right) & =\left\{u \in E_{M}\left(Q_{T}\right): \nabla_{x}^{\alpha} u \in E_{M}\left(Q_{T}\right),\right. \\
& \left.\forall \alpha \in \mathbb{N}^{N},|\alpha| \leq 1\right\} .
\end{aligned}
$$


The last space is a subspace of the first one, and both are Banach spaces under the norm $\|u\|=$ $\sum_{|\alpha| \leq m}\left\|\nabla_{x}^{\alpha} u\right\|_{M, Q_{T}}$. We can easily show that they form a complementary system when $\Omega$ satisfies the Lipschitz domain [17]. These spaces are considered as subspaces of the product space $\Pi L_{M}\left(Q_{T}\right)$ which have as many copies as there is $\alpha$-order derivatives, $|\alpha| \leq 1$. We shall also consider the weak topologies $\sigma\left(\Pi L_{M}, \Pi E_{\bar{M}}\right)$ and $\sigma\left(\Pi L_{M}, \Pi L_{\bar{M}}\right)$. If $u \in W^{1, x} L_{M}\left(Q_{T}\right)$ then the function : $t \mapsto u(t)=u(t,$.$) is defined on (0, T)$ with values $W^{1} L_{M}(\Omega)$. If, further, $u \in W^{1, x} E_{M}\left(Q_{T}\right)$ then the concerned function is a $W^{1, x} E_{M}(\Omega)$-valued and is strongly measurable. Furthermore the following imbedding holds $W^{1, x} E_{M}(\Omega) \subset L^{1}\left(0, T, W^{1, x} E_{M}(\Omega)\right)$. The space $W^{1, x} L_{M}\left(Q_{T}\right)$ is not in general separable, if $W^{1, x} L_{M}\left(Q_{T}\right)$, we can not conclude that the function $u(t)$ is measurable on $(0, T)$. However, the scalar function $t \mapsto\|u(t)\|_{M, \Omega}$, is in $L^{1}(0, T)$. The space $W_{0}^{1, x} E_{M}\left(Q_{T}\right)$ is defined as the (norm) closure $W^{1, x} E_{M}\left(Q_{T}\right)$ of $\mathcal{D}\left(Q_{T}\right)$. We can easily show as in [8],that when $\Omega$ has the segment property, then each element $u$ of the closure of $\mathcal{D}\left(Q_{T}\right)$ with respect of the weak ${ }^{*}$ topology $\sigma\left(\Pi L_{M}, \Pi E_{\bar{M}}\right)$ is a limit, in $W_{0}^{1, x} E_{M}\left(Q_{T}\right)$, of some subsequence $\left(u_{i}\right) \subset \mathcal{D}\left(Q_{T}\right)$ for the modular convergence; i.e. there exists $\lambda>0$ such that for all $|\alpha| \leq 1$

$$
\int_{Q_{T}} M\left(x, \frac{\nabla_{x}^{\alpha} u_{i}-\nabla_{x}^{\alpha} u}{\lambda}\right) d x d t \rightarrow 0 \quad \text { asi } \rightarrow \infty .
$$

This implies that $\left(u_{i}\right)$ converge to $u$ in $W^{1, x} L_{M}\left(Q_{T}\right)$ for the weak topology $\sigma\left(\Pi L_{M}, \Pi L_{\bar{M}}\right)$.

Consequently,

$$
{\overline{\mathcal{D}\left(Q_{T}\right)}}^{\sigma\left(\Pi L_{M}, \Pi E_{\bar{M}}\right)}={\overline{\mathcal{D}\left(Q_{T}\right)}}^{\sigma\left(\Pi L_{M}, \Pi L_{\bar{M}}\right)} .
$$

This space will be denoted by $W_{0}^{1, x} L_{M}\left(Q_{T}\right)$. Furthermore, $W_{0}^{1, x} E_{M}\left(Q_{T}\right)=W_{0}^{1, x} L_{M}\left(Q_{T}\right) \cap \Pi E_{M}$.

We have the following complementary system $\left(\begin{array}{cc}W_{0}^{1, x} L_{M}\left(Q_{T}\right) & F \\ W_{0}^{1, x} E_{M}\left(Q_{T}\right) & F_{0}\end{array}\right) F$ being the dual space of $W_{0}^{1, x} E_{M}\left(Q_{T}\right)$. It is also, except for an isomorphism, the quotient of $\Pi L_{\bar{M}}$ by the polar set $W_{0}^{1, x} E_{M}\left(Q_{T}\right)^{\perp}$, and will be denoted by $F=W^{-1, x} L_{\bar{M}}\left(Q_{T}\right)$ and it is show that,

$$
W^{-1, x} L_{\bar{M}}\left(Q_{T}\right)=\left\{f=\sum_{|\alpha| \leq 1} \nabla_{x}^{\alpha} f_{\alpha}: \quad f_{\alpha} \in L_{\bar{M}}\left(Q_{T}\right)\right\} .
$$

This space will be equipped with the usual quotient norm $\|f\|=\inf \sum_{|\alpha| \leq 1}\left\|f_{\alpha}\right\|_{\bar{M}, Q_{T}}$ where the infimum is taken on all possible decompositions $f=$ $\sum_{|\alpha| \leq 1} \nabla_{x}^{\alpha} f_{\alpha}, \quad f_{\alpha} \in L_{\bar{M}}\left(Q_{T}\right)$.

The space $F_{0}$ is then given by, $F_{0}=\left\{f=\sum_{|\alpha| \leq 1} \nabla_{x}^{\alpha} f_{\alpha}\right.$ : $\left.f_{\alpha} \in E_{\bar{M}}\left(Q_{T}\right)\right\}$ and is denoted by $F_{0}=W^{-1, x} E_{\bar{M}}\left(Q_{T}\right)$.

Theorem 2 [14] Let $\Omega$ be a bounded Lipchitz domain and let $M$ be a Musielak-Orlicz function satisfying the same conditions of Theorem 11. Then there exists a constant $\lambda>0$ such that $\|u\|_{M} \leq \lambda\|\nabla u\|_{M}, \quad \forall \in$ $W_{0}^{1} L_{M}\left(Q_{T}\right)$.

Definition 1 We say that $u_{n} \rightarrow u$ in $W^{-1, x} L_{\bar{M}}\left(Q_{T}\right)+$ $L^{1}\left(Q_{T}\right)$ for the modular convergence if we can write $u_{n}=\sum_{|\alpha| \leq 1} D_{x}^{\alpha} u_{n}^{\alpha}+u_{n}^{0}$ and $u=\sum_{|\alpha| \leq 1} D_{x}^{\alpha} u^{\alpha}+u^{0}$ with $u_{n}^{\alpha} \rightarrow u^{\alpha}$ in $L_{\bar{M}}\left(Q_{T}\right)$ for modular convergence for all $|\alpha| \leq 1$ and $u_{n}^{0} \rightarrow u^{0}$ strongly in $L^{1}\left(Q_{T}\right)$

Lemma 6 Let $\left\{u_{n}\right\}$ be a bounded sequence in $W^{1, x} L_{M}\left(Q_{T}\right)$ such that $\frac{\partial u_{n}}{\partial t}=\alpha_{n}+\beta_{n}$ in $\mathcal{D}^{\prime}\left(Q_{T}\right), u_{n} \rightarrow$ $u$, weakly in $W^{1, x} L_{M}\left(Q_{T}\right)$, for $\sigma\left(\Pi L_{M}, \Pi E_{\bar{M}}\right)$ with $\left\{\alpha_{n}\right\}$ and $\left\{\beta_{n}\right\}$ two bounded sequences respectively in $W^{-1, x} L \frac{}{M}\left(Q_{T}\right)$ and in $\mathcal{M}\left(Q_{T}\right)$. Then

$u_{n} \rightarrow u$ in $L_{\text {loc }}^{1}\left(Q_{T}\right)$. Furthermore, if $u_{n} \in W_{0}^{1, x} L_{M}\left(Q_{T}\right)$, then $u_{n} \rightarrow u$ strongly in $L^{1}\left(Q_{T}\right)$.

Theorem 3 if $u \in W^{1, x} L_{M}\left(Q_{T}\right) \cap L^{1}\left(Q_{T}\right)$ (resp. $\left.W_{0}^{1, x} L_{M}\left(Q_{T}\right) \cap L^{1}\left(Q_{T}\right)\right)$ and $\frac{\partial u}{\partial t} \in W^{-1, x} L_{\bar{M}}\left(Q_{T}\right)+L^{1}\left(Q_{T}\right)$ then there exists a sequence $\left(v_{j}\right)$ in $\mathcal{D}\left(\bar{Q}_{T}\right)$ (resp. $\left.\mathcal{D}\left(\bar{I}, \mathcal{D}\left(Q_{T}\right)\right)\right)$ such that $v_{j} \rightarrow u$ in $W^{1, x} L_{M}\left(Q_{T}\right)$ and $\frac{\partial v_{j}}{\partial t} \rightarrow \frac{\partial u}{\partial t}$ in $W^{-1, x} L_{\bar{M}}\left(Q_{T}\right)+L^{1}\left(Q_{T}\right)$ for the modular convergence.

Démonstration: Let $u \in W^{1, x} L_{M}\left(Q_{T}\right) \cap L^{1}\left(Q_{T}\right)$ and $\frac{\partial u}{\partial t} \in W^{-1, x} L_{\bar{M}}\left(Q_{T}\right)+L^{1}\left(Q_{T}\right)$, then for any $\epsilon>0$. Writing $\frac{\partial u}{\partial t}=\sum_{|\alpha| \leq 1} D_{x}^{\alpha} u^{\alpha}+u^{0}$, where $u^{\alpha} \in L_{\bar{M}}\left(Q_{T}\right)$ for all $|\alpha| \leq 1$ and $u^{0} \in L^{1}\left(Q_{T}\right)$, we will show that there exits $\lambda>0$ (depending Only on $u$ and $N$ ) and there exists $v \in \mathcal{D}\left(\bar{Q}_{T}\right)$ for which we can write $\frac{\partial u}{\partial t}=\sum_{|\alpha| \leq 1} D_{x}^{\alpha} v^{\alpha}+v^{0}$ with $v^{\alpha}, v^{0} \in \mathcal{D}\left(\bar{Q}_{T}\right)$ such that

$$
\begin{gathered}
\int_{Q_{T}} M\left(x, \frac{D_{x}^{\alpha} v-D_{x}^{\alpha} u}{\lambda}\right) d x d t \leq \epsilon, \forall|\alpha| \leq 1, \\
\|v-u\|_{L^{1}\left(Q_{T}\right)} \leq \epsilon, \\
\left\|v^{0}-u^{0}\right\|_{L^{1}\left(Q_{T}\right)} \leq \epsilon, \\
\int_{Q_{T}} \bar{M}\left(x, \frac{v^{\alpha}-u^{\alpha}}{\lambda}\right) d x d t \leq \epsilon, \forall|\alpha| \leq 1
\end{gathered}
$$

The equation (6) flows from a slight adaptation of the arguments [17], The equations (7), (8) flows also from classical approximation results. For The equation 9 we know that $\mathcal{D}\left(\bar{Q}_{T}\right)$ is dense in $L_{\bar{M}}\left(Q_{T}\right)$ for the modular convergence. The case where $u \in$ $\left.W_{0}^{1, x} L_{M}\left(Q_{T}\right) \cap L^{1}\left(Q_{T}\right)\right)$ can be handled similarly without essential difficulty as it mentioned [17].

Remark 2 The assumption $u \in L^{1}\left(Q_{T}\right)$ in theorem 3 is needed only when $Q_{T}$ has infinite measure, since else, we have $\left.L_{M}\left(Q_{T}\right)\right) \subset L^{1}\left(Q_{T}\right)$ and so $W^{1, x} L_{M}\left(Q_{T}\right) \cap L^{1}\left(Q_{T}\right)=$ $W^{1, x} L_{M}\left(Q_{T}\right)$.

Remark 3 If in the statement of theorem (3) above, one takes $I=\mathbb{R}$, we have that $\mathcal{D}(\Omega \times \mathbb{R})$ is dense in $\{u \in$ $\left.W_{0}^{1, x} L_{M}(\Omega \times \mathbb{R}) \cap L^{1} \Omega \times \mathbb{R}\right): \frac{\partial u}{\partial t} \in W^{-1, x} L_{\bar{M}}(\Omega \times \mathbb{R})+$ $\left.L^{1}(\Omega \times \mathbb{R})\right\}$ for the modular convergence. This trivially follows from the fact that $\mathcal{D}(\mathbb{R}, \mathcal{D}(\Omega))=\mathcal{D}(\Omega \times I R)$. 
Remark 4 Let $a<b \in \mathbb{R}$ and $\Omega$ be a bounded open subset of $\mathbb{R}^{N}$ with the segment property, then $\left\{u \in W_{0}^{1, x} L_{M}(\Omega \times\right.$ $\left.(a, b)) \cap L^{1} \Omega \times(a, b)\right): \frac{\partial u}{\partial t} \in W^{-1, x} L_{\bar{M}}(\Omega \times(a, b))+L^{1}(\Omega \times$ $(a, b))\} \subset \mathcal{C}\left([a, b], L^{1}(\Omega)\right)$.

Démonstration: Let $u \in W_{0}^{1, x} L_{M}(\Omega \times(a, b))$ and $\frac{\partial u}{\partial t} \in$ $W^{-1, x} L_{\bar{M}}(\Omega \times(a, b))+L^{1}(\Omega \times(a, b))$.

After two consecutive reflections first with respect to $t=b$ and then with respect to $t=a, \hat{u}(x, t)=$ $u(x, t) \chi_{(a, b)}+u(x, 2 b-t) \chi_{(b, 2 b-a)}$ in $\Omega \times(b, 2 b-a)$ and $\tilde{u}(x, t)=\hat{u}(x, t) \chi_{(a, 2 b-a)}+\hat{u}(x, 2 a-t) \chi_{(3 a-2 b, a)}$ in $\Omega \times$ $(3 a-2 b, 2 b-a)$. We get function $\tilde{u} \in W_{0}^{1, x} L_{M}(\Omega \times(3 a-$ $2 b, 2 b-a))$ with $\frac{\partial \tilde{u}}{\partial t} \in W^{-1, x} L_{\bar{M}}(\Omega \times(3 a-2 b, 2 b-a))+$ $L^{1}(\Omega \times(3 a-2 b, 2 b-a))$. Now by letting a function $\eta \in$ $\mathcal{D}(I R)$ with $\eta=1$ on $[a, b]$ and supp $\eta \subset(3 a-2 b, 2 b-a)$, we set $\bar{u}=\eta \tilde{u}$, therefore,by standard arguments (see [19]), we have $\bar{u}=u$ on $(\Omega \times(a, b)), \bar{u} \in W_{0}^{1, x} L_{M}(\Omega \times$ $I R) \cap L^{1}(\Omega \times \mathbb{R})$ and $\frac{\partial \bar{u}}{\partial t} \in W_{0}^{-1, x} L_{\bar{M}}(\Omega \times \mathbb{R})+L^{1}(\Omega \times \mathbb{R})$. Let now $v_{j}$ the sequence given by theorem 3 corresponding to $\bar{u}$, that is,

$$
v_{j} \rightarrow \bar{u} \quad \text { in } \quad W_{0}^{1, x} L_{M}(\Omega \times \mathbb{R})
$$

and

$$
\frac{\partial v_{j}}{\partial t} \rightarrow \frac{\partial \bar{u}}{\partial t} \quad \text { in } \quad W_{0}^{-1, x} L_{\bar{M}}(\Omega \times \mathbb{R})+L^{1}(\Omega \times \mathbb{R})
$$

for the modular convergence.

If we denote $S_{k}(s)=\int_{0}^{s} T_{k}(t) d t$ the primitive of $T_{k}$. and

We have, $\int_{\Omega} S_{1}\left(v_{i}-v_{j}\right)(\tau) d x=\int_{\Omega} \int_{-\infty}^{r} T_{1}\left(v_{i}-v_{j}\right)\left(\frac{\partial v_{i}}{\partial t}-\right.$ $\left.\frac{\partial v_{j}}{\partial t}\right) d x d t \rightarrow 0 \quad$ as $\quad i, j \rightarrow 0$, from which, one deduces that $v_{j}$ is a Cauchy sequence in $C\left(\mathbb{R} ; L^{1}(\Omega)\right)$ and hence $\bar{u} \in C\left(\mathbb{R}, L^{1}(\Omega)\right)$. Consequently, $u \in$ $C([a ; b] ; L 1(\Omega))$.

\section{Formulation of the problem and main results}

Let $\Omega$ be an open subset of $\mathbb{R}^{N}(N \geq 2)$ satisfying the segment property,and let $M$ and $P$ be two MusielakOrlicz functions such that $M$ and its complementary $\bar{M}$ satisfies conditions of Lemma $1, M$ is decreasing in $x$ and $P \prec \prec M$.

$b: \Omega \times \mathbb{R} \rightarrow \mathbb{R}$ is a Carathéodory function such that for every, $x \in \Omega, b(x,$.$) is a strictly increasing \mathcal{C}^{1}(\mathbb{R})$ function and

$$
b \in L^{\infty}(\Omega \times \mathbb{R}) \quad \text { with } \quad b(x, 0)=0,
$$

There exists a constant $\lambda>0$ and functions $A \in L^{\infty}(\Omega)$ and $B \in L_{M}(\Omega)$ such that

$$
\lambda \leq \frac{\partial b(x, s)}{\partial s} \leq A(x) \text { and }\left|\nabla_{x}\left(\frac{\partial b(x, s)}{\partial s}\right)\right| \leq B(x)
$$

a.e. $x \in \Omega$ and $\forall|s| \in \mathbb{R}$.

$A: D(A) \subset W_{0}^{1} L_{M}\left(Q_{T}\right) \rightarrow W^{-1} L_{\bar{M}}\left(Q_{T}\right)$ defined by $A(u)=-\operatorname{div} a(x, t, u, \nabla u)$, where $a: Q_{T} \times \mathbb{R} \times \mathbb{R}^{N} \rightarrow \mathbb{R}^{N}$ is caratheodory function such that for a.e. $x \in \Omega$ and for all $s \in \mathbb{R}, \xi, \xi^{*} \in \mathbb{R}^{N}, \xi \neq \xi^{*}$

$$
|a(x, t, s, \xi)| \leq v\left(a_{0}(x, t)+\bar{M}_{x}^{-1} P(x,|s|)\right),
$$

with $a_{0}(.,.) \in E_{\bar{M}}\left(Q_{T}\right)$,

$$
\begin{aligned}
& \left(a(x, t, s, \xi)-a\left(x, t, s, \xi^{*}\right)\right)\left(\xi-\xi^{*}\right)>0, \\
& a(x, t, s, \xi) . \xi \geq \alpha M(x,|\xi|)+M(x,|s|) .
\end{aligned}
$$

$\Phi(x, s, \xi): Q_{T} \times \mathbb{R} \times \mathbb{R}^{N} \rightarrow \mathbb{R}^{N}$ is a Carathéodory function such that

$$
|\Phi(x, t, s)| \leq c(x, t) \bar{M}_{x}^{-1} M\left(x, \alpha_{0}|s|\right),
$$

where $c(.,.) \in L^{\infty}\left(Q_{T}\right),\|c(., .)\|_{L^{\infty}\left(Q_{T}\right)} \leq \alpha$, and

$0<\alpha_{0}<\min \left(1, \frac{1}{\alpha}\right)$.

$H(x, t, s, \xi): Q_{T} \times \mathbb{R} \times \mathbb{R}^{N} \rightarrow \mathbb{R}$ is a Carathéodory function such that

$$
|H(x, t, s, \xi)| \leq h(x, t)+\rho(s) M(x,|\xi|),
$$

$\rho: \mathbb{R} \rightarrow \mathbb{R}^{+}$is continuous positive function which belong $L^{1}(I R)$ and $h(.,$.$) belong L^{1}\left(Q_{T}\right)$.

$$
f \in L^{1}(\Omega)
$$

$$
u_{0} \in L^{1}(\Omega) \text { such that } b\left(x, u_{0}\right) \in L^{1}(\Omega) .
$$

Note that $<,>$ means for either the pairing between $\left.W_{0}^{1, x} L_{M}\left(Q_{T}\right) \cap L^{\infty}\left(Q_{T}\right)\right)$ and $W^{-1, x} L_{\bar{M}}\left(Q_{T}\right)+L^{1}\left(Q_{T}\right)$ or between $W_{0}^{1, x} L_{M}\left(Q_{T}\right)$ and $W^{-1, x} L_{\bar{M}}\left(Q_{T}\right)$.

Weak entropy solution: The definition of a entropy solution of Problem 1 can be stated as follows,

Definition 2 A measurable function $u$ defined on $Q_{T}$ is a entropy solution of Problem (1), if it satisfies the following conditions:

$b(x, u) \in L^{\infty}\left(0, T ; L^{1}(\Omega)\right), b(x, u)(t=0)=b\left(x, u_{0}\right) \quad$ in $\Omega$,

$$
\left.\left.T_{k}(u) \in W_{0}^{1, x} L_{M}\left(Q_{T}\right), \quad \forall k>0, \quad \forall t \in\right] 0, T\right],
$$

$$
\left\{\begin{array}{l}
\int_{0}^{T}\left\langle\frac{\partial v}{\partial s} ; \int_{0}^{u} \frac{\partial b(x, z)}{\partial s} T_{k}^{\prime}(z-v) d z\right\rangle d s \\
+\int_{\Omega} \int_{0}^{u_{0}} \frac{\partial b(x, s)}{\partial s} T_{k}(s-v(0)) d s d x \\
+\int_{Q_{T}} a(u, \nabla u) \nabla T_{k}(u-v) d x d s+\int_{Q_{T}} \Phi(u) \nabla T_{k}(u-v) d x d s \\
+\int_{Q_{T}} H(u, \nabla u) T_{k}(u-v) d x d s \leq \int_{Q_{T}} f T_{k}(u-v) d x d s \\
\forall k>0, \quad \text { and } \quad \forall v \in W^{1, x} L_{M}\left(Q_{T}\right) \cap L^{\infty}\left(Q_{T}\right) \quad \text { with } \\
\quad v(T)=0, \quad \text { such that } \quad \frac{\partial v}{\partial t} \in W^{-1, x} L_{M}\left(Q_{T}\right)+L^{1}\left(Q_{T}\right)
\end{array}\right.
$$

Theorem 4 Assume that 11 - 18 hold true. Then there exists at least one solution $u$ of the following problem (19.) 


\section{Proof of theorem 4}

\section{Truncated problem.}

For each $n>0$, we define the following approximations

$$
\begin{gathered}
b_{n}(x, s)=b\left(x, T_{n}(s)\right)+\frac{1}{n} s \quad \forall r \in \mathbb{R}, \\
a_{n}(x, t, s, \xi)=a\left(x, t, T_{n}(s), \xi\right) \quad \text { a.e. }(x, t) \in Q_{T},
\end{gathered}
$$

$\forall s \in \mathbb{R}, \forall \xi \in \mathbb{R}^{N}$,

$$
\Phi_{n}(x, t, s)=\Phi\left(x, t, T_{n}(s)\right) \text { a.e. }(x, t) \in Q_{T}, \forall s \in \mathbb{R},
$$

$$
H_{n}(x, t, s, \xi)=\frac{H(x, t, s, \xi)}{1+\frac{1}{n}|H(x, t, s, \xi)|},
$$

$f_{n} \in L^{1}\left(Q_{T}\right)$ such that $f_{n} \rightarrow f$ strongly in $L^{1}\left(Q_{T}\right)$,

$$
\text { and }
$$$$
\text { and }\left\|f_{n}\right\|_{L^{1}\left(Q_{T}\right)} \leq\|f\|_{L^{1}\left(Q_{T}\right)}
$$

$$
u_{0 n} \in \mathcal{C}_{0}^{\infty}(\Omega) \text { such that } b_{n}\left(x, u_{0 n}\right) \rightarrow b\left(x, u_{0}\right)
$$

strongly in $L^{1}(\Omega)$.

Let us now consider the approximate problem :

$$
\left\{\begin{array}{l}
\frac{\partial b_{n}\left(x, u_{n}\right)}{\partial t}-\operatorname{div}\left(a_{n}\left(x, t, u_{n}, \nabla u_{n}\right)\right)-\operatorname{div}\left(\Phi_{n}\left(x, t, u_{n}\right)\right) \\
+H_{n}\left(x, u_{n}, \nabla u_{n}\right)=f_{n} \text { in } Q_{T} \\
u_{n}(x, t)=0 \text { on } \partial \Omega \times(0, T) \\
b_{n}\left(x, u_{n}\right)(t=0)=b_{n}\left(x, u_{0 n}\right) \text { in } \Omega .
\end{array}\right.
$$

Since $H_{n}$ is bounded for any fixed $n>0$, there exists at last one solution $u_{n} \in W_{0}^{1, x} L_{M}\left(Q_{T}\right)$ of 26 (see [20]).

Remark 5 the explicit dependence in $x$ and $t$ of the functions $a, \Phi$ and $H$ will be omitted so that $a(x, t, u, \nabla u)=$ $a(u, \nabla u), \Phi(x, t, u)=\Phi(u)$ and $H(x, t, u, \nabla u)=H(u, \nabla u)$.

Proposition 1 let $u_{n}$ be a solution of approximate equation (26) such that

$$
\left\{\begin{array}{l}
T_{k}\left(u_{n}\right) \rightarrow T_{k}(u) \text { weakly in } W^{1, x} L_{M}\left(Q_{T}\right), \\
u_{n} \rightarrow u \text { a.e. in } Q_{T}, \\
b_{n}\left(x, u_{n}\right) \rightarrow b(x, u) \text { a.e. in } Q_{T} \text { and } b(x, u) \in L^{\infty}(Q \\
a\left(T_{k}\left(u_{n}\right), \nabla T_{k}\left(u_{n}\right)\right) \nabla T_{k}\left(u_{n}\right) \rightarrow a\left(T_{k}(u), \nabla T_{k}(u)\right) \nabla T_{k}(u) \\
\quad \text { weakly in } L^{1}\left(Q_{T}\right) \\
\nabla u_{n} \rightarrow \nabla u \text { a.e. in } Q_{T}, \\
H_{n}\left(u_{n}, \nabla u_{n}\right) \rightarrow H(u, \nabla u) \text { strongly in } L^{1}\left(Q_{T}\right) .
\end{array}\right.
$$

then $u$ be a solution of problem (19).

Démonstration: Let $v \in W_{0}^{1} L_{M}\left(Q_{T}\right) \cap L^{\infty}\left(Q_{T}\right)$ such that $\frac{\partial v}{\partial t} \in W^{-1, x} L_{\bar{M}}\left(Q_{T}\right)+L^{1}\left(Q_{T}\right)$ with $v(T)=0$, then by theorem 3 we can take $\bar{v}=v$ on $Q_{T}, \bar{v} \in W^{1, x} L_{M}(\Omega \times$ $I R) \cap L^{1}(\Omega \times \mathbb{R}) \cap L^{\infty}(\Omega \times \mathbb{R}), \frac{\partial \bar{v}}{\partial t} \in W^{-1, x} L_{\bar{M}}\left(Q_{T}\right)+L^{1}\left(Q_{T}\right)$, and there exists $v_{j} \in \mathcal{D}(\Omega \times \mathbb{R})$ such that $v_{j}(T)=0$, $v_{j} \rightarrow \bar{v} \quad$ in $W_{0}^{1, x} L_{M}(\Omega \times I R)$ and

$$
\frac{\partial v_{j}}{\partial t} \rightarrow \frac{\partial \bar{v}}{\partial t} \in W^{-1, x} L_{\bar{M}}\left(Q_{T}\right)+L^{1}\left(Q_{T}\right)
$$

for the modular convergence in $W_{0}^{1} L_{M}\left(Q_{T}\right)$, with $\left\|v_{j}\right\|_{L^{\infty}\left(Q_{T}\right)} \leq(N+2)\|v\|_{L^{\infty}\left(Q_{T}\right)}$.
Pointwise multiplication of the approximate equation 26) by $T_{k}\left(u_{n}-v_{j}\right)$, we get

$$
\left\{\begin{array}{l}
\int_{0}^{T}<\frac{\partial b_{n}\left(x, u_{n}\right)}{\partial s} ; T_{k}\left(u_{n}-v_{j}\right)>d s \\
+\int_{Q_{T}} a_{n}\left(u_{n}, \nabla u_{n}\right) \nabla T_{k}\left(u_{n}-v_{j}\right) d x d s \\
+\int_{Q_{T}}^{Q_{n}} \Phi_{n}\left(u_{n}\right) \nabla T_{k}\left(u_{n}-v_{j}\right) d x d s \\
+\int_{Q_{T}} H_{n}\left(u_{n}, \nabla u_{n}\right) \nabla T_{k}\left(u_{n}-v_{j}\right) d x d s \\
=\int_{Q_{T}} f_{n} T_{k}\left(u_{n}-v_{j}\right) d x d s
\end{array}\right.
$$

We pass to the limit as in 29, $n$ tend to $+\infty$ and $j$ tend to $+\infty$ :

Limit of the first term of 29]:

The first term can be written

$$
\begin{aligned}
\int_{0}^{T}<\frac{\partial b_{n}\left(x, u_{n}\right)}{\partial s} ; T_{k}\left(u_{n}-v_{j}\right)>d s \\
=\int_{0}^{T}<\frac{\partial v}{\partial s} ; \int_{0}^{u_{n}} \frac{\partial b_{n}(x, z)}{\partial s} T_{k}^{\prime}\left(z-v_{j}\right)>d s \\
\quad+\int_{\Omega} \int_{0}^{u_{n}(T)} \frac{\partial b_{n}(x, s)}{\partial s} T_{k}\left(s-v_{j}(T)\right) d s d x \\
\quad-\int_{\Omega} \int_{0}^{u_{0 n}} \frac{\partial b_{n}(x, s)}{\partial s} T_{k}\left(s-v_{j}(0)\right) d s d x,
\end{aligned}
$$

the fact that $\frac{\partial b_{n}(x, s)}{\partial s} \geq 0$ and $v_{j}(T)=0$, we get

$$
\begin{gathered}
\int_{\Omega} \int_{0}^{u(T)} \frac{\partial b(x, s)}{\partial s} T_{k}\left(s-v_{j}(T)\right) d s d x= \\
\int_{\Omega} \int_{0}^{u(T)} \frac{\partial b(x, s)}{\partial s} T_{k}(s) d s d x \geq 0
\end{gathered}
$$

On the other hand, we have $u_{0 n}$ converge to $u_{0}$ strongly in $L^{1}(\Omega)$, then

$\lim _{n \rightarrow+\infty} \int_{\Omega} \int_{0}^{u_{0 n}} \frac{\partial b_{n}(x, s)}{\partial s} T_{k}\left(s-v_{j}(0)\right) d s d x$

$$
=\int_{\Omega} \int_{0}^{u_{0}} \frac{\partial b(x, s)}{\partial s} T_{k}\left(s-v_{j}(0)\right) d s d x,
$$

With $M=k+(N+2)\|v\|_{\infty}$ and $T_{M}\left(u_{n}\right)$ converges to $T_{M}(u)$ strongly in $E_{M}\left(Q_{T}\right)$, we obtain

$$
\begin{aligned}
& \lim _{n \rightarrow+\infty} \int_{0}^{T}<\frac{\partial v_{j}}{\partial t} ; \int_{0}^{u_{n}} \frac{\partial b_{n}(x, z)}{\partial s} T_{k}^{\prime}\left(z-v_{j}\right) d z>d s \\
= & \lim _{n \rightarrow+\infty} \int_{0}^{T}<\frac{\partial v_{j}}{\partial s} ; \int_{0}^{T_{M}\left(u_{n}\right)} \frac{\partial b_{n}(x, z)}{\partial s} T_{k}^{\prime}\left(z-v_{j}\right) d z>d s \\
= & \int_{0}^{T}<\frac{\partial v_{j}}{\partial s} ; \int_{0}^{T_{M}(u)} \frac{\partial b(x, z)}{\partial s} T_{k}^{\prime}\left(z-v_{j}\right) d z>d s,
\end{aligned}
$$

then

$\int_{0}^{T}<\frac{\partial v_{j}}{\partial s} ; \int_{0}^{T_{M}(u)} \frac{\partial b(x, z)}{\partial s} T_{k}^{\prime}\left(z-v_{j}\right) d z>d s$

$$
\leq \lim _{n \rightarrow+\infty} \int_{0}^{T}<\frac{\partial b\left(x, u_{n}\right)}{\partial s} T_{k}\left(u_{n}-v_{j}\right)>d s
$$$$
+\int_{\Omega} \int_{0}^{u_{0}}<\frac{\partial b(x, s)}{\partial s} T_{k}\left(s-v_{j}(0)\right)>d s d x,
$$ 
using (28), the definition of $T_{k}$ and pass to limit as $j \rightarrow+\infty$, we deduce

$$
\begin{aligned}
\int_{0}^{T}< & \frac{\partial v}{\partial s} ; \int_{0}^{T_{M}(u)} \frac{\partial b(x, z)}{\partial s} T_{k}^{\prime}(z-v) d z>d s \\
\leq & \lim _{j \rightarrow+\infty} \lim _{n \rightarrow+\infty} \int_{0}^{T}<\frac{\partial b\left(x, u_{n}\right)}{\partial s} T_{k}\left(u_{n}-v_{j}\right)>d s \\
& +\int_{\Omega} \int_{0}^{u_{0}}<\frac{\partial b(x, t)}{\partial s} T_{k}(s-v(0))>d s d x
\end{aligned}
$$

- We can follow same way in [21] to prove that

$$
\begin{gathered}
\liminf _{j \rightarrow \infty} \liminf _{n \rightarrow \infty} \int_{Q_{T}} a\left(u_{n}, \nabla u_{n}\right) \nabla T_{k}\left(u_{n}-v_{j}\right) d x d s \\
\geq \int_{Q_{T}} a(u, \nabla u) \nabla T_{k}(u-v) d x d s .
\end{gathered}
$$

- For $n \geq k+(N+2)\|v\|_{L^{\infty}\left(Q_{T}\right)} \Phi_{n}\left(u_{n}\right) \nabla T_{k}\left(u_{n}-v_{j}\right)=$

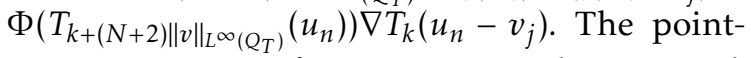
wise convergence of $u_{n}$ to $u$ as $n$ tends to $+\infty$ and

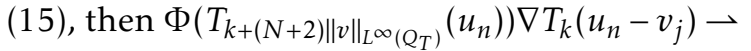
$\Phi\left(T_{k+(N+2)\|v\|_{L^{\infty}\left(Q_{T}\right)}}(u)\right) \nabla T_{k}\left(u-v_{j}\right)$ weakly for $\sigma\left(\Pi L_{M}, \Pi L_{\bar{M}}\right)$.

In a similar way, we obtain

$$
\begin{aligned}
& \lim _{j \rightarrow \infty} \int_{Q_{T}} \Phi\left(T_{k+(N+2)\|v\|_{L^{\infty}\left(Q_{T}\right)}}(u)\right) \nabla T_{k}\left(u-v_{j}\right) d x d s \\
& =\int_{Q_{T}} \Phi\left(T_{k+(N+2)\|v\|_{L^{\infty}\left(Q_{T}\right)}}(u)\right) \nabla T_{k}(u-v) d x d s \\
& =\int_{Q_{T}} \Phi(u) \nabla T_{k}(u-v) d x d s .
\end{aligned}
$$

- Limit of $H_{n}\left(u_{n}, \nabla u_{n}\right) T_{k}\left(u_{n}-v_{j}\right)$ :

Since $H_{n}\left(u_{n}, \nabla u_{n}\right)$ converge strongly to $H(x, s, u, \nabla u)$ in $L^{1}\left(Q_{T}\right)$ and the pointwise convergence of $u_{n}$ to $u$ as $n \rightarrow+\infty$, it is possible to prove that $H_{n}\left(u_{n}, \nabla u_{n}\right) T_{k}\left(u_{n}-v_{j}\right)$ converge to $H(u, \nabla u) T_{k}\left(u-v_{j}\right)$ in $L^{1}\left(Q_{T}\right)$ and $\lim _{j \rightarrow \infty} \int_{Q_{T}} H(u, \nabla u) T_{k}\left(u-v_{j}\right) d x d s=$ $\int_{Q_{T}} H(u, \nabla u) T_{k}(u-v) d x d s$.

- Since $f_{n}$ converge strongly to $f$ in $L^{1}\left(Q_{T}\right)$, and $T_{k}\left(u_{n}-v_{j}\right) \rightarrow T_{k}\left(u_{n}-v_{j}\right)$ weakly* in $L^{\infty}\left(Q_{T}\right)$, we have $\int_{Q_{T}} f_{n} T_{k}\left(u_{n}-v_{j}\right) d x d s \rightarrow \int_{Q_{T}} f T_{k}\left(u-v_{j}\right) d x d s$ as $n \rightarrow \infty$ and also we have

$\int_{Q_{T}} f T_{k}\left(u-v_{j}\right) d x d s \rightarrow \int_{Q_{T}} f T_{k}(u-v) d x d s$ as $j \rightarrow \infty$

Finally, the above convergence result, we are in a position to pass to the limit as $n$ tends to $+\infty$ in equation 29) and to conclude that $u$ satisfies (19).

It remains to show that $b(x, u)$ satisfies the initial condition. In fact, remark that, $B_{M}\left(x, u_{n}\right)=$ $\int_{0}^{u_{n}} \frac{\partial b(x, s)}{\partial s} T_{M}(s-v) d s$ is bounded in $L^{\infty}\left(Q_{T}\right)$. Secondly, by 69 we show that $\frac{\partial B_{M}\left(x, u_{n}\right)}{\partial t}$ is bounded in
$\left.W^{-1, x} L_{\bar{M}}\left(Q_{T}\right)\right)+L^{1}\left(Q_{T}\right)$. As a consequence, a Lemma 4 implies that $B_{M}\left(x, u_{n}\right)$ lies in a compact set of $C^{0}\left([0, T] ; L^{1}(\Omega)\right)$. It follows that, $B_{M}\left(x, u_{n}\right)(t=0)$ converges to $B_{M}(x, u)(t=0)$ strongly in $L^{1}(\Omega)$. On the order hand, the smoothness of $B_{M}$ imply that $B_{M}\left(x, u_{n}\right)(t=0)$ converges to $B_{M}(x, u)(t=0)$ strongly in $L^{1}(\Omega)$, we conclude that $B_{M}\left(x, u_{n}\right)(t=0)=B_{M}\left(x, u_{0 n}\right)$ converges to $B_{M}(x, u)(t=0)$ strongly in $L^{1}(\Omega)$, we obtain $B_{M}(x, u)(t=0)=B_{M}\left(x, u_{0}\right)$ a.e. in $\Omega$ and for all $M>0$, now letting $M$ to $+\infty$, we conclude that $b(x, u)(t=0)=b\left(x, u_{0}\right)$ a.e. in $\Omega$.

Remark 6 We focus our work to show the conditions of the proposition 27, then for this we go through 4 steps to arrive at our result.

Step 1: In this step let us begin by showing

\section{Lemma 7}

Let $\left\{u_{n}\right\}_{n}$ be a solution of the approximate problem (26), then for all $k>0$, there exists a constants $C_{1}$ and $C_{2}$ such that

$$
\int_{Q_{T}} a\left(T_{k}\left(u_{n}\right), \nabla T_{k}\left(u_{n}\right)\right) \nabla T_{k}\left(u_{n}\right) d x d t \leq k C_{1},
$$

and

$$
\int_{Q_{T}} M\left(x,\left|\nabla T_{k}\left(u_{n}\right)\right|\right) d x d t \leq k C_{2},
$$

where $C_{1}$ and $C_{2}$ does not depend on the $n$ and $k$.

Démonstration: Fixed $k>0$,

Let $\tau \in(0, T)$ and using $\exp \left(G\left(u_{n}\right)\right) T_{k}\left(u_{n}\right)^{+} \chi_{(0, \tau)}$ as a test function in problem $(26)$, where

$G(s)=\int_{0}^{s} \frac{\rho(r)}{\alpha^{\prime}} d r$ and $\alpha^{\prime}>0$ is a parameter to be specified later, we get:

$$
\begin{aligned}
& \int_{Q_{\tau}} \frac{\partial b_{n}\left(x, u_{n}\right)}{\partial s} \exp \left(G\left(u_{n}\right)\right) T_{k}\left(u_{n}\right)^{+} \chi_{(0, t)} d x d t \\
& +\int_{Q_{\tau}} a\left(u_{n}, \nabla u_{n}\right) \frac{\rho\left(u_{n}\right)}{\alpha^{\prime}} \exp \left(G\left(u_{n}\right)\right) \nabla u_{n} T_{k}\left(u_{n}\right)^{+} d x d t \\
& +\int_{\left\{0 \leq u_{n} \leq k\right\}} a\left(u_{n}, \nabla u_{n}\right) \exp \left(G\left(u_{n}\right)\right) \nabla T_{k}\left(u_{n}\right) d x d t \\
& +\int_{Q_{\tau}} \Phi_{n}\left(u_{n}\right) \nabla\left(\exp \left(G\left(u_{n}\right)\right) T_{k}\left(u_{n}\right)^{+}\right) d x d t \\
& +\int_{Q_{\tau}} H\left(u_{n}, \nabla u_{n}\right) \exp \left(G\left(u_{n}\right)\right) T_{k}\left(u_{n}\right)^{+} d x d t \\
& \leq k \exp \left(\frac{\|\rho\|_{L^{1}}}{\alpha^{\prime}}\right)\left\|f_{n}\right\|_{L^{1}\left(Q_{T}\right)} .
\end{aligned}
$$

For the 32), we have

$$
\begin{aligned}
& \int_{Q_{\tau}} \frac{\partial b_{n}\left(x, u_{n}\right)}{\partial s} \exp \left(G\left(u_{n}\right)\right) T_{k}\left(u_{n}\right)^{+} \chi_{(0, \tau)} d x d t \\
& \quad=\int_{\Omega} B_{n, k}\left(x, u_{n}(\tau)\right) d x-\int_{\Omega} B_{n, k}\left(x, u_{n}(0)\right) d x,
\end{aligned}
$$


where

$$
B_{n, k}(x, r)=\int_{0}^{r} \frac{\partial b_{n}(x, s)}{\partial s} \exp \left(G\left(T_{k}(s)\right)\right) T_{k}(s)^{+} d s .
$$

By (11), we have $\int_{\Omega} B_{n, k}\left(x, u_{n}(\tau)\right) d x \geq 0$ and

$$
\int_{Q_{\tau}} B_{n, k}\left(x, u_{n}(0)\right) d x \leq k \exp \left(\frac{\|\rho\|_{L^{1}}}{\alpha^{\prime}}\right) \| b\left(x, u_{0} \|_{L^{1}(\Omega)} .\right.
$$

For the 35 , if we use 15 and Young inequality, we get

$\left.\int_{Q_{\tau}} \Phi_{n}\left(u_{n}\right)\right) \nabla\left(\exp \left(G\left(u_{n}\right)\right) T_{k}\left(u_{n}\right)^{+}\right) d x d t \leq$

$\frac{\|c(., .)\|_{L^{\infty}\left(Q_{T}\right)}}{\alpha^{\prime}}\left[\alpha_{0} \int_{Q_{\tau}} M\left(x, u_{n}\right) \rho\left(u_{n}\right) \exp \left(G\left(u_{n}\right)\right) T_{k}\left(u_{n}\right)^{+} d x d t-\frac{\|c(., .)\|_{L^{\infty}\left(Q_{T}\right)}}{\alpha}\right] \int_{Q_{\tau}} a\left(u_{n}, \nabla u_{n}\right) \exp \left(G\left(u_{n}\right)\right) \nabla T_{k}\left(u_{n}\right)^{+} d x d t \leq k C$.

$\left.+\int_{Q_{\tau}} M\left(x, \nabla u_{n}\right) \rho\left(u_{n}\right) \exp \left(G\left(u_{n}\right)\right) T_{k}\left(u_{n}\right)^{+} d x d t\right]$

$+\|c(., .)\|_{L^{\infty}\left(Q_{T}\right)} \alpha_{0} \int_{Q_{\tau}} M\left(x, u_{n}\right) \exp \left(G\left(u_{n}\right)\right) d x d t$

$+\|c(., .)\|_{L^{\infty}\left(Q_{T}\right)} \int_{Q_{\tau}} M\left(x,\left|\nabla T_{k}\left(u_{n}\right)^{+}\right|\right) \exp \left(G\left(u_{n}\right)\right) d x d t$.

For the 36, we have,

$$
\begin{aligned}
& \int_{Q_{\tau}} H_{n}\left(u_{n}, \nabla u_{n}\right) \exp \left(G\left(u_{n}\right)\right) T_{k}\left(u_{n}\right)^{+} d x d t \\
& \quad \leq k \exp \left(\frac{\|\rho\|_{L^{1}}}{\alpha^{\prime}}\right) \int_{Q_{T}}|h(x, t)| d x d t \\
& +\int_{Q_{\tau}} \rho\left(u_{n}\right) \exp \left(G\left(u_{n}\right)\right) M\left(x, \nabla T_{k}\left(u_{n}\right)\right) T_{k}\left(u_{n}\right)^{+} d x d t .
\end{aligned}
$$

finally using the previous inequalities and (14), we obtain

$$
\left\{\begin{array}{l}
\frac{1}{\alpha^{\prime}} \int_{Q_{\tau}} M\left(x, u_{n}\right) \rho\left(u_{n}\right) \exp \left(G\left(u_{n}\right)\right) T_{k}\left(u_{n}\right)^{+} d x d t \\
+\frac{\alpha}{\alpha^{\prime}} \int_{Q_{\tau}} M\left(x, \nabla u_{n}\right) \rho\left(u_{n}\right) \exp \left(G\left(u_{n}\right)\right) T_{k}\left(u_{n}\right)^{+} d x d t \\
+\int_{Q_{\tau}} a\left(u_{n}, \nabla u_{n}\right) \exp \left(G\left(u_{n}\right)\right) \nabla T_{k}\left(u_{n}\right)^{+} d x d t \\
\leq \frac{\|c(. .)\|_{L^{\infty}\left(Q_{T}\right)}}{\alpha^{\prime}}\left[\alpha_{0} \int_{Q_{\tau}} M\left(x, u_{n}\right) \rho\left(u_{n}\right) \exp \left(G\left(u_{n}\right)\right) T_{k}\left(u_{n}\right)^{+} d x\right. \\
\left.+\int_{Q_{\tau}} M\left(x, \nabla u_{n}\right) \rho\left(u_{n}\right) \exp \left(G\left(u_{n}\right)\right) T_{k}\left(u_{n}\right)^{+} d x d t\right] \\
+\alpha_{0}\|c(., .)\|_{L^{\infty}\left(Q_{T}\right)} \int_{\left\{0 \leq u_{n} \leq k\right\}} M\left(x, u_{n}\right) \exp \left(G\left(u_{n}\right)\right) d x d t \\
+\|c(., .)\|_{L^{\infty}\left(Q_{T}\right)} \int_{Q_{\tau}} M\left(x, \nabla T_{k}\left(u_{n}\right)^{+}\right) \exp \left(G\left(u_{n}\right)\right) d x d t \\
+\int_{Q_{\tau}} M\left(x, \nabla u_{n}\right) \rho\left(u_{n}\right) \exp \left(G\left(u_{n}\right)\right) T_{k}\left(u_{n}\right)^{+} d x d t \\
+k\left[\operatorname { e x p } \left(\frac { \| \rho \| _ { L ^ { 1 } } } { \alpha ^ { \prime } } \left(\|f\|_{L^{1}\left(Q_{T}\right)}+\| b\left(x, u_{0} \|_{L^{1}(\Omega)}\right.\right.\right.\right. \\
\left.+\int_{Q_{T}}|h(x, t)| d x d t\right],
\end{array}\right.
$$

we deduce,

which becomes after simplification,

$$
\left\{\begin{array}{l}
{\left[\frac{1-\alpha_{0}\|c(., .)\|_{L^{\infty}\left(Q_{T}\right)}}{\alpha^{\prime}}\right] \int_{Q_{\tau}} M\left(x, u_{n}\right) \rho\left(u_{n}\right) \exp \left(G\left(u_{n}\right)\right) T_{k}\left(u_{n}\right)^{+} d x d t} \\
+\left[\frac{\alpha-\| c\left(. ., \|_{L^{\infty}\left(Q_{T}\right)}-\alpha^{\prime}\right.}{\alpha^{\prime}}\right] \int_{Q_{\tau}} M\left(x, \nabla u_{n}\right) \rho\left(u_{n}\right) \exp \left(G\left(u_{n}\right)\right) T_{k}\left(u_{n}\right)^{+} d x d t \\
+\int_{Q_{\tau}} a\left(u_{n}, \nabla u_{n}\right) \exp \left(G\left(u_{n}\right)\right) \nabla T_{k}\left(u_{n}\right)^{+} d x d t \\
\leq \frac{\|c(., .)\|_{L^{\infty}\left(Q_{T}\right)}}{\alpha}\left[\alpha_{0} \alpha \int_{\left\{0 \leq u_{n} \leq k\right\}} M\left(x, u_{n}\right) \exp \left(G\left(u_{n}\right)\right) d x d t\right. \\
\left.+\alpha M\left(x, \nabla T_{k}\left(u_{n}\right)^{+}\right) \exp \left(G\left(u_{n}\right)\right) d x d t\right]+k C .
\end{array}\right.
$$

If we choose $\alpha^{\prime}$ such that $\alpha^{\prime}<\alpha-\|c(., .)\|_{L^{\infty}\left(Q_{T}\right)}$ and using again 14 in 39 we get

$$
\int_{\left\{0 \leq u_{n} \leq k\right\}} a\left(u_{n}, \nabla u_{n}\right) \exp \left(G\left(u_{n}\right)\right) \nabla T_{k}\left(u_{n}\right) d x d t \leq k c_{1} .
$$

one has $\exp \left(G\left(u_{n}\right)\right) \geq 1$ for in $\left\{(x, t) \in Q_{T}: 0 \leq u_{n} \leq k\right\}$ then

$$
\int_{\left\{0 \leq u_{n} \leq k\right\}} a\left(u_{n}, \nabla u_{n}\right) \nabla T_{k}\left(u_{n}\right) d x d t \leq k c_{1} .
$$

and by 14 another again

$$
\int_{Q_{t}} M\left(x,\left|\nabla T_{k}\left(u_{n}\right)^{+}\right|\right) d x d t \leq k c_{2} .
$$

Similarly, taking $\exp \left(-G\left(u_{n}\right) T_{k}\left(u_{n}\right)^{-} \chi_{(0, \tau)}\right.$ as a test function in problem 26 , we get

$$
\begin{gathered}
\int_{Q_{\tau}} \frac{\partial b_{n}\left(x, u_{n}\right)}{\partial t} \exp \left(-G\left(u_{n}\right)\right) T_{k}\left(u_{n}\right)^{-} d x d t \\
+\int_{Q_{\tau}} a_{n}\left(u_{n}, \nabla u_{n}\right) \nabla\left(\exp \left(-G\left(u_{n}\right)\right) \nabla T_{k}\left(u_{n}\right)^{-}\right) d x d t \\
+\int_{Q_{\tau}} \Phi_{n}\left(u_{n}\right) \nabla\left(\exp \left(-G\left(u_{n}\right)\right) \nabla T_{k}\left(u_{n}\right)^{-}\right) d x d t \\
+\int_{Q_{\tau}} H\left(u_{n}, \nabla u_{n}\right) \exp \left(-G\left(u_{n}\right)\right) T_{k}\left(u_{n}\right)^{-} d x d t \\
\geq \int_{Q_{\tau}} f_{n} \exp \left(-G\left(u_{n}\right)\right) T_{k}\left(u_{n}\right)^{-} d x d t .
\end{gathered}
$$

and using same techniques above, we obtain

$$
\int_{\left\{-k \leq u_{n} \leq 0\right\}} a\left(u_{n}, \nabla u_{n}\right) \nabla T_{k}\left(u_{n}\right) d x d t \leq k c_{1} .
$$

since $\exp \left(-G\left(u_{n}\right)\right) \geq 1$ in $\left\{(x, t) \in Q_{T}:-k \leq u_{n} \leq 0\right\}$ and

$$
\int_{Q_{\tau}} M\left(x,\left|\nabla T_{k}\left(u_{n}\right)^{-}\right|\right) d x d t \leq k c_{2} .
$$

Combining now 41 and 48 we get,

$$
\int_{Q_{\tau}} a\left(u_{n}, \nabla u_{n}\right) \nabla T_{k}\left(u_{n}\right) d x d t \leq k C_{1},
$$

in the same with 42 and 49 we get,

$$
\int_{Q_{\tau}} M\left(x,\left|\nabla T_{k}\left(u_{n}\right)\right|\right) d x d t \leq k C_{2} .
$$


we conclude that $T_{k}\left(u_{n}\right)$ is bounded in $W_{0}^{1, x} L_{M}\left(Q_{T}\right)$ independently of $n$, and for any $k>0$, so there exists a subsequence still denoted by $u_{n}$ such that

$$
T_{k}\left(u_{n}\right) \rightarrow \xi_{k} \quad \text { weakly in } \quad W_{0}^{1, x} L_{M}\left(Q_{T}\right)
$$

On the other hand, using 51 , we have

$$
\begin{gathered}
M\left(x, \frac{k}{\delta}\right) \text { meas }\left\{\left|u_{n}\right|>k\right\} \leq \int_{\left\{\left|u_{n}\right|>k\right\}} M\left(x, \frac{\left|T_{k}\left(u_{n}\right)\right|}{\delta}\right) d x d t \\
\leq \int_{Q_{T}} M\left(x,\left|\nabla T_{k}\left(u_{n}\right)\right|\right) d x d t \leq k C_{2},
\end{gathered}
$$

then

$$
\operatorname{meas}\left\{\left|u_{n}\right|>k\right\} \leq \frac{k C_{2}}{M\left(x, \frac{k}{\delta}\right)},
$$

for all $n$ and for all $k$.

Assuming that there exists a positive function $M$ such that $\lim _{t \rightarrow \infty} \frac{M(t)}{t}=+\infty$ and $M(t) \leq e s \operatorname{sinf}_{x \in \Omega} M(x, t)$, $\forall t \geq 0$. thus, we get

$$
\lim _{k \rightarrow \infty} \text { meas }\left\{\left|u_{n}\right|>k\right\}=0 .
$$

Now we turn to prove the almost every convergence of $u_{n}, b_{n}\left(x, u_{n}\right)$ and $a_{n}\left(x, t, T_{k}\left(u_{n}\right), \nabla T_{k}\left(u_{n}\right)\right)$.

Proposition 2 Let $u_{n}$ be a solution of the approximate problem, then

$$
\begin{gathered}
u_{n} \rightarrow u \text { a.e in } Q_{T}, \\
b_{n}\left(x, u_{n}\right) \rightarrow b(x, u) \quad \text { a.e in } Q_{T} \quad \text { and } \\
b(x, u) \in L^{\infty}\left(0, T, L^{1}(\Omega)\right), \\
a_{n}\left(T_{k}\left(u_{n}\right), \nabla T_{k}\left(u_{n}\right)\right) \rightarrow \omega_{k} \quad \text { in }\left(L_{\bar{M}}\left(Q_{T}\right)\right)^{N}, \\
\text { for } \sigma\left(\Pi L_{\bar{M}}, \Pi E_{M}\right),
\end{gathered}
$$

for some $\omega_{k} \in\left(L_{\bar{M}}\left(Q_{T}\right)\right)^{N}$.

\section{Démonstration: :}

Proof of 53) and 54):

Proceeding as in [22], we have for any $S \in W^{2, \infty}(I R)$, such that $S^{\prime}$, has a compact support

(suppS $\left.S^{\prime} \subset[-K, K]\right)$.

$$
B_{S}^{n}\left(x, u_{n}\right) \quad \text { is bounded in } W_{0}^{1, x} L_{M}\left(Q_{T}\right),
$$

and

$$
\frac{\partial B_{S}^{n}\left(x, u_{n}\right)}{\partial t} \text { is bounded in } L^{1}\left(Q_{T}\right)+W^{-1, x} L_{\bar{M}}\left(Q_{T}\right),
$$

independently of $n$.

Indeed, we have first

$$
\left|\nabla B_{S}^{n}\left(x, u_{n}\right)\right| \leq\left\|A_{K}\right\|_{L^{\infty}(\Omega)} \mid D T_{k}\left(u_{n}\right)\|\| S^{\prime}\left\|_{L^{\infty}(\Omega)}+K\right\| S^{\prime} \|_{L^{\infty}(\Omega)} B
$$

a.e. in $Q_{T}$.

As a consequence of (58) and 51) we then obtain 56).

To show that 57 holds true, we multiply the equation

(26) by $S^{\prime}\left(u_{n}\right)$, to obtain

$\frac{\partial B_{S}^{n}\left(x, u_{n}\right)}{\partial t}=\operatorname{div}\left(S^{\prime}\left(u_{n}\right) a_{n}\left(u_{n}, \nabla u_{n}\right)\right)-S^{\prime \prime}\left(u_{n}\right) a_{n}\left(u_{n}, \nabla u_{n}\right) \nabla u_{n}$

$$
\begin{gathered}
\quad+\operatorname{div}\left(S^{\prime}\left(u_{n}\right) \Phi_{n}\left(u_{n}\right)\right)-S^{\prime \prime}\left(u_{n}\right) \Phi_{n}\left(u_{n}\right) \nabla u_{n} \\
+H_{n}\left(u_{n}, \nabla u_{n}\right) S^{\prime}\left(u_{n}\right)+f_{n} S^{\prime}\left(u_{n}\right) \text { in } \mathcal{D}\left(Q_{T}\right) .
\end{gathered}
$$

where $B_{S}^{n}(x, r)=\int_{0}^{r} S^{\prime}(s) \frac{\partial b_{n}(x, s)}{\partial s} d s$. Since supp $S^{\prime}$ and suppS" are both included in $[-K, K], u_{n}$ may be replaced by $T_{k}\left(u_{n}\right)$ in each of these terms. As a consequence, each term in the right hand side of 59 is bounded either in $W^{-1, x} L_{\bar{M}}\left(Q_{T}\right)$ or in $L^{1}\left(Q_{T}\right)$ which shows that 57) holds true.

Arguing again as in [22] estimates (56), 57) and the following remark (1), we can show (53) and (54). Proof of 55:

The same way in [15], we deduce that $a_{n}\left(T_{k}\left(u_{n}\right), \nabla T_{k}\left(u_{n}\right)\right)$ is a bounded sequence in $\left(L_{\bar{M}}\left(Q_{T}\right)\right)^{N}$, and we obtain 55 .

Step 2: This technical lemma will help us in the step 3 of the demonstration,

Lemma 8 If the subsequence $u_{n}$ satisfies [26, then

$$
\lim _{m \rightarrow+\infty} \limsup _{n \rightarrow+\infty} \int_{\left\{m \leq\left|u_{n}\right| \leq m+1\right\}} a\left(u_{n}, \nabla u_{n}\right) \nabla u_{n} d x d t=0 .
$$

Démonstration: Taking the function $Z_{m}\left(u_{n}\right)=T_{1}\left(u_{n}-\right.$ $\left.T_{m}\left(u_{n}\right)\right)^{-}$and multiplying the approximating equation 26 by the test function $\exp \left(-G\left(u_{n}\right)\right) Z_{m}\left(u_{n}\right)$ we get

$$
\left\{\begin{array}{l}
\int_{Q_{T}} B_{n, m}\left(x, u_{n}(T)\right) d x \\
+\int_{Q_{T}} a_{n}\left(u_{n}, \nabla u_{n}\right) \nabla\left(\exp \left(-G\left(u_{n}\right)\right) Z_{m}\left(u_{n}\right)\right) d x d t \\
+\int_{Q_{T}}^{\Phi_{n}} \Phi_{n}\left(u_{n}\right) \nabla\left(\exp \left(-G\left(u_{n}\right)\right) Z_{m}\left(u_{n}\right)\right) d x d t \\
+\int_{Q_{T}} H_{n}\left(u_{n}, \nabla u_{n}\right) \exp \left(-G\left(u_{n}\right)\right) Z_{m}\left(u_{n}\right) d x d t \\
=\int_{Q_{T}} f_{n} \exp \left(-G\left(u_{n}\right)\right) Z_{m}\left(u_{n}\right) d x d t+\int_{Q_{T}} B_{n, m}\left(x, u_{0 n}\right) d x
\end{array}\right.
$$

where $B_{n, m}(x, r)=\int_{0}^{r} \frac{\partial b_{n}(x, s)}{\partial s} \exp (-G(s)) Z_{m}(s) d s$.

Using the same argument in step 2, we obtain

$$
\begin{gathered}
\int_{Q_{T}} M\left(x,\left|\nabla Z_{m}\left(u_{n}\right)\right|\right) d x d t \leq C\left(\int_{Q_{T}}|h(x, t)| Z_{m}\left(u_{n}\right) d x d t\right. \\
\left.\quad+\int_{Q_{T}} f_{n} Z_{m}\left(u_{n}\right) d x d t+\int_{\left|u_{0 n}\right|>m}\left|b_{n}\left(x, u_{0 n}\right)\right| d x\right) .
\end{gathered}
$$

where

$$
C=\exp \left(\frac{\|\rho\|_{L^{1}}}{\alpha^{\prime}}\right)\left(\frac{\alpha}{\alpha-\|c(., .)\|_{L^{\infty}\left(Q_{T}\right)}}\right) .
$$

(as)sing to limit as $n \rightarrow+\infty$, since the pointwise conver gence of $u_{n}$ and strongly convergence in $L^{1}\left(Q_{T}\right)$ of $f_{n}$ and $b_{n}\left(x, u_{0 n}\right)$ we get

$$
\lim _{n \rightarrow+\infty} \int_{Q_{T}} M\left(x,\left|\nabla Z_{m}\left(u_{n}\right)\right|\right) d x d t \leq C\left(\int_{Q_{T}} f Z_{m}(u) d x d t\right.
$$

$$
\left.+\int_{Q_{T}}|h(x, t)| Z_{m}(u) d x d t+\int_{\left\{\left|u_{0}\right|>m\right\}}\left|b\left(x, u_{0}\right)\right| d x\right) .
$$


By using Lebesgue's theorem and passing to limit as $m \rightarrow+\infty$, in the all term of the right-hand side, we get

$$
\lim _{m \rightarrow+\infty} \lim _{n \rightarrow+\infty} \int_{Q_{T}} M\left(x,\left|\nabla Z_{m}\left(u_{n}\right)\right|\right) d x d t=0,
$$

On the other hand, by (15) and Young inequality,for $n>m+1$ we obtain

$$
\begin{aligned}
& \int_{Q_{T}}\left|\Phi_{n}\left(x, t, u_{n}\right) \exp \left(-G\left(u_{n}\right)\right) \nabla Z_{m}\left(u_{n}\right)\right| d x d t \\
& \leq \exp \left(\frac{\|\rho\|_{L^{1}}}{\alpha^{\prime}}\right)\left[\int_{\left\{-(m+1) \leq u_{n} \leq-m\right\}} M\left(x, \alpha_{0}\left|T_{m+1}\left(u_{n}\right)\right|\right) d x d t\right. \\
& \left.\quad+\int_{Q_{T}} M\left(x,\left|\nabla Z_{m}\left(u_{n}\right)\right|\right) d x d t\right] .
\end{aligned}
$$

Using the pointwise convergence of $u_{n}$ and by Lebesgues theorem, it follows,

$$
\begin{gathered}
\lim _{n \rightarrow+\infty} \int_{Q_{T}}\left|\Phi_{n}\left(u_{n}\right) \exp \left(-G\left(u_{n}\right)\right) \nabla Z_{m}\left(u_{n}\right)\right| d x d t \\
\leq \exp \left(\frac{\|\rho\|_{L^{1}}}{\alpha^{\prime}}\right)\left[\int_{\{-(m+1) \leq u \leq-m\}} M\left(x, \alpha_{0}\left|T_{m+1}(u)\right|\right) d x d t\right. \\
\left.\quad+\lim _{n \rightarrow+\infty} \int_{Q_{T}} M\left(x,\left|\nabla Z_{m}\left(u_{n}\right)\right|\right) d x d t\right]
\end{gathered}
$$

passing to the limit in as $m \rightarrow+\infty$, we get

$$
\lim _{m \rightarrow+\infty} \lim _{n \rightarrow+\infty} \int_{Q_{T}} \Phi_{n}\left(u_{n}\right) \exp \left(-G\left(u_{n}\right)\right) \nabla Z_{m}\left(u_{n}\right) d x d t=0 .
$$

Finally passing to the limit in $(61)$, we get

$$
\lim _{m \rightarrow+\infty} \lim _{n \rightarrow+\infty} \int_{\left\{-(m+1) \leq u_{n} \leq-m\right\}} a_{n}\left(u_{n}, \nabla u_{n}\right) \nabla u_{n} d x d t=0,
$$

In the same way we take $Z_{m}\left(u_{n}\right)=T_{1}\left(u_{n}-T_{m}\left(u_{n}\right)\right)^{+}$and multiplying the approximating equation (26) by the test function $\exp \left(G\left(u_{n}\right)\right) Z_{m}\left(u_{n}\right)$ and we also obtain

$$
\lim _{m \rightarrow+\infty} \lim _{n \rightarrow+\infty} \int_{\left\{m \leq u_{n} \leq m+1\right\}} a_{n}\left(u_{n}, \nabla u_{n}\right) \nabla u_{n} d x d t=0,
$$

on the above we get 60 .

Step 3: Almost everywhere convergence of the gradients.

This step is devoted to introduce a time regularization of the $T_{k}(u)$ for $k>0$ in order to perform the monotonicity method.

Lemma 9 (See [23]) Under assumptions 11- 18, and let $\left(z_{n}\right)$ be a sequence in $W_{0}^{1, x} L_{M}\left(Q_{T}\right)$ such that:

$$
\begin{gathered}
z_{n} \rightarrow z \text { for } \sigma\left(\Pi L_{M}\left(Q_{T}\right), \Pi E_{\bar{M}}\left(Q_{T}\right)\right) \\
\left(a\left(x, t, z_{n}, \nabla z_{n}\right)\right) \quad \text { is bounded in }\left(L_{\bar{M}}\left(Q_{T}\right)\right)^{N} \\
\int_{Q_{T}}\left[a\left(x, t, z_{n}, \nabla z_{n}\right)-a\left(x, t, z_{n}, \nabla z \chi_{s}\right)\right]\left[\nabla z_{n}-\nabla z \chi_{s}\right] d x d t \rightarrow 0,
\end{gathered}
$$

as $n$ and s tend to $+\infty$, and where $\chi_{s}$ is the characteristic function of $Q_{s}=\left\{(x, t) \in Q_{T} ;|\nabla z| \leq s\right\}$ then,

$$
\nabla z_{n} \rightarrow \nabla z \quad \text { a.e. in } Q_{T} \text {, }
$$

$\lim _{n \rightarrow+\infty} \int_{Q_{T}} a\left(x, t, z_{n}, \nabla z_{n}\right) \nabla z_{n} d x d t=\int_{Q_{T}} a(x, t, z, \nabla z) \nabla z d x d t$

$$
M\left(x,\left|\nabla z_{n}\right|\right) \rightarrow M(x,|\nabla z|) \quad \text { in } L^{1}\left(Q_{T}\right)
$$

Let $v_{j} \in \mathcal{D}\left(Q_{T}\right)$ be a sequence such that $v_{j} \rightarrow u$ in $W_{0}^{1, x} L_{M}\left(Q_{T}\right)$ for the modular convergence.

This specific time regularization of $T_{k}\left(v_{j}\right)$ (for fixed $k \geq 0$ ) is defined as follows.

Let $\left(\alpha_{0}^{\mu}\right)_{\mu}$ be a sequence of functions defined on $\Omega$ such that

$$
\begin{gathered}
\alpha_{0}^{\mu} \in L^{\infty}(\Omega) \cap W_{0}^{1} L_{M}(\Omega) \text { for all } \mu>0, \\
\left\|\alpha_{0}^{\mu}\right\|_{L^{\infty}(\Omega)} \leq k, \text { for all } \mu>0,
\end{gathered}
$$

and $\alpha_{0}^{\mu}$ converges to $T_{k}\left(u_{0}\right)$ a.e. in $\Omega$ and $\frac{1}{\mu}\left\|\alpha_{0}^{\mu}\right\|_{M, \Omega}$ converges to 0 as $\mu \rightarrow+\infty$.

For $k \geq 0$ and $\mu>0$, let us consider the unique solution $\left(T_{k}\left(v_{j}\right)\right)_{\mu} \in L^{\infty}\left(Q_{T}\right) \cap W_{0}^{1, x} L_{M}\left(Q_{T}\right)$ of the monotone problem:

$$
\begin{gathered}
\frac{\partial\left(T_{k}\left(v_{j}\right)\right)_{\mu}}{\partial t}+\mu\left(\left(T_{k}\left(v_{j}\right)\right)_{\mu}-T_{k}\left(v_{j}\right)\right)=0 \text { in } D^{\prime}(\Omega), \\
\left(T_{k}\left(v_{j}\right)\right)_{\mu}(t=0)=\alpha_{0}^{\mu} \text { in } \Omega .
\end{gathered}
$$

Remark that due to

$$
\frac{\partial\left(T_{k}\left(v_{j}\right)\right)_{\mu}}{\partial t} \in W_{0}^{1, x} L_{M}\left(Q_{T}\right)
$$

We just recall that, $\left(T_{k}\left(v_{j}\right)\right)_{\mu} \rightarrow T_{k}(u)$ a.e. in $Q_{T}$, weakly-* in $L^{\infty}\left(Q_{T}\right)$,

$\left(T_{k}\left(v_{j}\right)\right)_{\mu} \rightarrow\left(T_{k}(u)\right)_{\mu}$ in $W_{0}^{1, x} L_{M}\left(Q_{T}\right)$ for the modular convergence as $j \rightarrow+\infty$ and

$\left(T_{k}(u)\right)_{\mu} \rightarrow T_{k}(u)$ in $W_{0}^{1, x} L_{M}\left(Q_{T}\right)$, for the modular convergence as $\mu \rightarrow+\infty$.

$\left\|\left(T_{k}\left(v_{j}\right)\right)_{\mu}\right\|_{L^{\infty}\left(Q_{T}\right)} \leq \max \left(\left\|\left(T_{k}(u)\right)\right\|_{L^{\infty}\left(Q_{T}\right)},\left\|\alpha_{0}^{\mu}\right\|_{L^{\infty}(\Omega)}\right) \leq k$,

$\forall \mu>0, \forall k>0$.

We introduce a sequence of increasing $C^{1}(I R)$-functions $S_{m}$ such that $S_{m}(r)=1$ for $|r| \leq m, \quad S_{m}(r)=m+1-$ $|r|, \quad$ for $\quad m \leq|r| \leq m+1, \quad S_{m}(r)=0 \quad$ for $\quad|r| \geq m+1$ for any $m \geq 1$ and we denote by $\epsilon(n, \mu, \eta, j, m)$ the quantities such that

$$
\lim _{m \rightarrow+\infty} \lim _{j \rightarrow+\infty} \lim _{\eta \rightarrow+\infty} \lim _{\mu \rightarrow+\infty} \lim _{n \rightarrow+\infty} \epsilon(n, \mu, \eta, j, m)=0,
$$

the main estimate is

For fixed $k \geq 0$, let $W_{\mu, \eta}^{n, j}=T_{\eta}\left(T_{k}\left(u_{n}\right)-T_{k}\left(v_{j}\right)_{\mu}\right)^{+}$and $W_{\mu, \eta}^{j}=T_{\eta}\left(T_{k}(u)-T_{k}\left(v_{j}\right)_{\mu}\right)^{+}$.

Multiplying the approximating equation by $\left.\exp \left(G\left(u_{n}\right)\right)\right) W_{\mu, \eta}^{n, j} S_{m}\left(u_{n}\right)$ and using the same technique in step 2 we obtain: 


$$
\left\{\begin{array}{l}
\int_{Q_{T}}<\frac{\partial b_{n}\left(x, u_{n}\right)}{\partial t} \exp \left(G\left(u_{n}\right)\right) W_{\mu, \eta}^{n, j} S_{m}\left(u_{n}\right) d x d t \\
+\int_{Q_{T}} a_{n}\left(u_{n}, \nabla u_{n}\right) \exp \left(G\left(u_{n}\right)\right) \nabla\left(W_{\mu, \eta}^{n, j}\right) S_{m}\left(u_{n}\right) d x d t \\
+\int_{Q_{T}} a_{n}\left(u_{n}, \nabla u_{n}\right) \nabla u_{n} \exp \left(G\left(u_{n}\right)\right) W_{\mu, \eta}^{n, j} S_{m}^{\prime}\left(u_{n}\right) d x d t \\
-\int_{Q_{T}}^{\Phi_{n}} \Phi_{n}\left(u_{n}\right) \exp \left(G\left(u_{n}\right)\right) \nabla\left(W_{\mu, \eta}^{n, j}\right) S_{m}\left(u_{n}\right) d x d t \\
-\int_{Q_{T}} \Phi_{n}\left(u_{n}\right) \nabla u_{n} \exp \left(G\left(u_{n}\right)\right) W_{\mu, \eta}^{n, j} S_{m}^{\prime}\left(u_{n}\right) d x d t \\
\leq \int_{Q_{T}} f_{n} \exp \left(G\left(u_{n}\right)\right) W_{\mu, \eta}^{n, j} S_{m}\left(u_{n}\right) d x d t \\
+\int_{Q_{T}} h(x, t) \exp \left(G\left(u_{n}\right)\right) W_{\mu, \eta}^{n, j} S_{m}\left(u_{n}\right) d x d t .
\end{array}\right.
$$

Now we pass to the limit in 70 for $k$ real number fixed.

In order to perform this task we prove below the following results for any fixed $k \geq 0$ :

$$
\int_{Q_{T}} \frac{\partial b_{n}\left(x, u_{n}\right)}{\partial t} \exp \left(G\left(u_{n}\right)\right) W_{\mu, \eta}^{n, j} S_{m}\left(u_{n}\right) d x d t \geq \epsilon(n, \mu, \eta, j)
$$

for any $m \geq 1$,

$$
\int_{Q_{T}} \Phi_{n}\left(u_{n}\right) S_{m}\left(u_{n}\right) \exp \left(G\left(u_{n}\right)\right) \nabla\left(W_{\mu, \eta}^{n, j}\right) d x d t=\epsilon(n, j, \mu)
$$

for any $m \geq 1$,

$$
\int_{Q_{T}} \Phi_{n}\left(u_{n}\right) \nabla u_{n} S_{m}^{\prime}\left(u_{n}\right) \exp \left(G\left(u_{n}\right)\right) W_{\mu, \eta}^{n, j} d x d t=\epsilon(n, j, \mu)
$$

for any $m \geq 1$,

$$
\begin{gathered}
\int_{Q_{T}} a_{n}\left(u_{n}, \nabla u_{n}\right) \nabla u_{n} S_{m}^{\prime}\left(u_{n}\right) \exp \left(G\left(u_{n}\right)\right) W_{\mu, \eta}^{n, j} d x d t \\
\leq \epsilon(n, m), \\
\int_{Q_{T}} a_{n}\left(u_{n}, \nabla u_{n}\right) S_{m}\left(u_{n}\right) \exp \left(G\left(u_{n}\right)\right) \nabla\left(W_{\mu, \eta}^{n, j}\right) d x d t \\
\leq C \eta+\epsilon(n, j, \mu, m), \\
\int_{Q_{T}} f_{n} S_{m}\left(u_{n}\right) \exp \left(G\left(u_{n}\right)\right) W_{\mu, \eta}^{n, j} d x d t \\
+\int_{Q_{T}} h(x, t) \exp \left(G\left(u_{n}\right)\right) W_{\mu, \eta}^{n, j} S_{m}\left(u_{n}\right) d x d t \\
\leq C \eta+\epsilon(n, \eta), \\
\int_{Q_{T}}\left[a\left(T_{k}\left(u_{n}\right), \nabla T_{k}\left(u_{n}\right)\right)-a\left(x, t, T_{k}\left(u_{n}\right), \nabla T_{k}(u)\right)\right] \\
\times\left[\nabla T_{k}\left(u_{n}\right)-\nabla T_{k}(u)\right] d x d t \rightarrow 0 .
\end{gathered}
$$

Proof of (71):

\section{Lemma 10}

$$
\int_{Q_{T}} \frac{\partial b_{n}\left(x, u_{n}\right)}{\partial t} \exp \left(G\left(u_{n}\right)\right) W_{\mu, \eta}^{n, j} S_{m}\left(u_{n}\right) d x d t \geq \epsilon(n, \mu, \eta, \eta, j)
$$

$m \geq 1$.
Démonstration: We adopt the same technics in the proof in [8].

Proof of (72): If we take $n>m+1$, we get $\Phi_{n}\left(u_{n}\right) \exp \left(G\left(u_{n}\right)\right) S_{m}\left(u_{n}\right)=$

$$
\Phi\left(T_{m+1}\left(u_{n}\right)\right) \exp \left(G\left(T_{m+1}\left(u_{n}\right)\right)\right) S_{m}\left(T_{m+1}\left(u_{n}\right)\right),
$$

then $\Phi_{n}\left(u_{n}\right) \exp \left(G\left(u_{n}\right)\right) S_{m}\left(u_{n}\right)$ is bounded in $L_{\bar{M}}(Q)$, thus, by using the pointwise convergence of $u_{n}$ and Lebesgue's theorem we obtain

$$
\Phi_{n}\left(u_{n}\right) \exp \left(G\left(u_{n}\right)\right) S_{m}\left(u_{n}\right) \rightarrow \Phi(u) \exp (G(u)) S_{m}(u),
$$

with the modular convergence as $n \rightarrow+\infty$, then $\Phi_{n}\left(u_{n}\right) \exp \left(G\left(u_{n}\right)\right) S_{m}\left(u_{n}\right) \rightarrow \Phi(u) \exp (G(u)) S_{m}(u)$ for $\sigma\left(\Pi L_{\bar{M}}, \Pi L_{M}\right)$.

On the other hand $\nabla W_{\mu, \eta}^{n, j}=\nabla T_{k}\left(u_{n}\right)-$ $\nabla\left(T_{k}\left(v_{j}\right)\right)_{\mu}$ for $\left|T_{k}\left(u_{n}\right)-\left(T_{k}\left(v_{j}\right)\right)_{\mu}\right| \leq \eta$ converge to $\nabla T_{k}(u)-\nabla\left(T_{k}\left(v_{j}\right)\right)_{\mu}$ weakly in $\left(L_{M}\left(Q_{T}\right)\right)^{N}$, then $\int_{Q_{T}} \Phi_{n}\left(u_{n}\right) \exp \left(G\left(u_{n}\right)\right) S_{m}\left(u_{n}\right) \nabla W_{\mu, \eta}^{n, j} d x d t \rightarrow$ $\int_{Q_{T}} \Phi(u) S_{m}(u) \exp (G(u)) \nabla W_{\mu, \eta}^{j} d x d t$, as $n \rightarrow+\infty$.

using the modular convergence of $W_{\mu, \eta}^{j}$ as $j \rightarrow+\infty$ and letting $\mu$ tends to infinity, we get (72).

Proof of (73): For $n>m+1>k$, we have $\nabla u_{n} S_{m}^{\prime}\left(u_{n}\right)=\nabla T_{m+1}\left(u_{n}\right)$ a.e. in $Q_{T}$. By the almost every where convergence of $u_{n}$ we have $\exp \left(G\left(u_{n}\right)\right) W_{\mu, \eta}^{n, j} \rightarrow$ $\exp (G(u)) W_{\mu, \eta}^{j}$ in $L^{\infty}\left(Q_{T}\right)$ weak-* and since the sequence $\left(\Phi_{n}\left(T_{m+1}\left(u_{n}\right)\right)\right)_{n}$ converge strongly in $E_{\bar{M}}\left(Q_{T}\right)$ then $\Phi_{n}\left(T_{m+1}\left(u_{n}\right)\right) \exp \left(G\left(u_{n}\right)\right) \quad W_{\mu, \eta}^{n, j} \rightarrow$ $\Phi\left(x, t, T_{m+1}(u)\right) \exp (G(u)) W_{\mu, \eta}^{j}$, converge strongly in $E_{\bar{M}}\left(Q_{T}\right)$ as $n \rightarrow+\infty$. By virtue of $\nabla T_{m+1}\left(u_{n}\right) \rightarrow$ $\nabla T_{m+1}(u)$ weakly in $\left(L_{M}\left(Q_{T}\right)\right)^{N}$ as $n \rightarrow+\infty$ we have

$$
\begin{gathered}
\int_{\left\{m \leq\left|u_{n}\right| \leq m+1\right\}} \Phi_{n}\left(T_{m+1}\left(u_{n}\right)\right) \nabla u_{n} S_{m}^{\prime}\left(u_{n}\right) \exp \left(G\left(u_{n}\right)\right) W_{\mu, \eta}^{n, j} d x d t \\
\rightarrow \int_{\{m \leq|u| \leq m+1\}} \Phi(u) \nabla u \exp (G(u)) W_{\mu, \eta}^{j} d x d t
\end{gathered}
$$

as $n \rightarrow+\infty$.

with the modular convergence of $W_{\mu, \eta}^{j}$ as $j \rightarrow+\infty$ and letting $\mu \rightarrow+\infty$ we get (73).

Proof of (74): we have

$$
\int_{Q_{T}} a_{n}\left(u_{n}, \nabla u_{n}\right) S_{m}^{\prime}\left(u_{n}\right) \nabla u_{n}
$$

$$
\times \exp \left(G\left(u_{n}\right)\right) \exp \left(G\left(u_{n}\right)\right) W_{\mu, \eta}^{n, j} d x d t
$$

$=\int_{\left\{m \leq\left|u_{n}\right| \leq m+1\right\}} a_{n}\left(u_{n}, \nabla u_{n}\right) S_{m}^{\prime}\left(u_{n}\right) \nabla u_{n}$

$$
\times \exp \left(G\left(u_{n}\right)\right) W_{\mu, \eta}^{n, j} d x d t
$$

$\leq \eta C \int_{\left\{m \leq\left|u_{n}\right| \leq m+1\right\}} a_{n}\left(u_{n}, \nabla u_{n}\right) \nabla u_{n} d x d t$.

Using 60, we get

$\int_{Q_{T}} a_{n}\left(u_{n}, \nabla u_{n}\right) S_{m}^{\prime}\left(u_{n}\right) \nabla u_{n} \exp \left(G\left(u_{n}\right)\right) W_{\mu, \eta}^{n, j} d x d s$ 
Proof of (76): Since $S_{m}(r) \leq 1$ and $W_{\mu, \eta}^{n, j} \leq \eta$ we get

$$
\begin{gathered}
\int_{Q_{T}} f_{n} S_{m}\left(u_{n}\right) \exp \left(G\left(u_{n}\right)\right) W_{\mu, \eta}^{n, j} \quad d x d t \leq \epsilon(n, \eta), \\
\int_{Q_{T}} h(x, t) \exp \left(G\left(u_{n}\right)\right) W_{\mu, \eta}^{n, j} S_{m}\left(u_{n}\right) d x d t \leq C \eta .
\end{gathered}
$$

Proof of 75):

$$
\begin{gathered}
\int_{Q_{T}} a_{n}\left(u_{n}, \nabla u_{n}\right) S_{m}\left(u_{n}\right) \exp \left(G\left(u_{n}\right)\right) \nabla W_{\mu, \eta}^{n, j} d x d t \\
=\int_{\left.\left\{\left|u_{n}\right| \leq k\right\} \cap\left\{0 \leq T_{k}\left(u_{n}\right)-T_{k}\left(v_{j}\right)_{\mu}\right) \leq \eta\right\}} a_{n}\left(T_{k}\left(u_{n}\right), \nabla T_{k}\left(u_{n}\right)\right) \\
\times S_{m}\left(u_{n}\right) \exp \left(G\left(u_{n}\right)\right)\left(\nabla T_{k}\left(u_{n}\right)-\nabla T_{k}\left(v_{j}\right)_{\mu}\right) d x d t \\
-\int_{\left.\left\{\left|u_{n}\right|>k\right\} \cap\left\{0 \leq T_{k}\left(u_{n}\right)-T_{k}\left(v_{j}\right)_{\mu}\right) \leq \eta\right\}} a_{n}\left(u_{n}, \nabla u_{n}\right) \\
\quad \times S_{m}\left(u_{n}\right) \exp \left(G\left(u_{n}\right)\right) \nabla T_{k}\left(v_{j}\right)_{\mu} d x d t
\end{gathered}
$$

Since $a_{n}\left(T_{k+\eta}\left(u_{n}\right), \nabla T_{k+\eta}\left(u_{n}\right)\right)$ is bounded in $\left(L_{\bar{M}}\left(Q_{T}\right)\right)^{N}$ there exist some $\omega_{k+\eta} \in\left(L_{\bar{M}}\left(Q_{T}\right)\right)^{N}$ such that $a_{n}\left(T_{k+\eta}\left(u_{n}\right), \nabla T_{k+\eta}\left(u_{n}\right)\right) \rightarrow \omega_{k+\eta}$ weakly in $\left(L_{\bar{M}}\left(Q_{T}\right)\right)^{N}$.

Consequently,

$$
\begin{gathered}
\int_{\left.\left\{\left|u_{n}\right|>k\right\} \cap\left\{0 \leq T_{k}\left(u_{n}\right)-T_{k}\left(v_{j}\right)_{\mu}\right) \leq \eta\right\}} a_{n}\left(u_{n}, \nabla u_{n}\right) S_{m}\left(u_{n}\right) \\
\exp \left(G\left(u_{n}\right)\right) \nabla T_{k}\left(v_{j}\right)_{\mu} d x d t \\
=\int_{\left.\{|u|>k\} \cap\left\{0 \leq T_{k}(u)-T_{k}\left(v_{j}\right)_{\mu}\right) \leq \eta\right\}} \omega_{k+\eta} \\
\times S_{m}(u) \exp (G(u)) \nabla T_{k}\left(v_{j}\right)_{\mu} d x d t+\epsilon(n),
\end{gathered}
$$

where we have used the fact that

$\left.S_{m}\left(u_{n}\right) \exp \left(G\left(u_{n}\right)\right) \nabla T_{k}\left(v_{j}\right)_{\mu}\right) \chi_{\left.\left\{\left|u_{n}\right|>k\right\} \cap\left\{0 \leq T_{k}\left(u_{n}\right)-T_{k}\left(v_{j}\right)_{\mu}\right) \leq \eta\right\}}$

$\left.\rightarrow S_{m}(u) \exp (G(u)) \nabla T_{k}\left(v_{j}\right)_{\mu}\right) \chi_{\left.\{|u|>k\} \cap\left\{0 \leq T_{k}(u)-T_{k}\left(v_{j}\right)_{\mu}\right) \leq \eta\right\}}$

strongly in $\left(E_{M}\left(Q_{T}\right)\right)^{N}$.

Letting $j \rightarrow+\infty$, we obtain

$\int_{\left.\{|u|>k\} \cap\left\{0 \leq T_{k}(u)-T_{k}\left(v_{j}\right)_{\mu}\right) \leq \eta\right\}} \omega_{k+\eta}$

$$
\begin{gathered}
S_{m}(u) \exp (G(u)) \nabla T_{k}\left(v_{j}\right)_{\mu} d x d t \\
=\int_{\left.\{|u|>k\} \cap\left\{0 \leq T_{k}(u)-T_{k}(u)_{\mu}\right) \leq \eta\right\}} \omega_{k+\eta} \\
S_{m}(u) \exp (G(u)) \nabla T_{k}(u)_{\mu} d x d t+\epsilon(n, j),
\end{gathered}
$$

$$
\leq C \eta+\epsilon(n, j, \mu, m),
$$

we know that $\exp \left(G\left(u_{n}\right)\right) \geq 1$ and $S_{m}\left(u_{n}\right)=1$ for $\left|u_{n}\right| \leq k$ then

$$
\begin{aligned}
& \int_{\left.\left\{\left|u_{n}\right| \leq k\right\} \cap\left\{0 \leq T_{k}\left(u_{n}\right)-T_{k}\left(v_{j}\right)_{\mu}\right) \leq \eta\right\}} a_{n}\left(x, t, T_{k}\left(u_{n}\right), \nabla T_{k}\left(u_{n}\right)\right) \\
& \times\left(\nabla T_{k}\left(u_{n}\right)-\nabla T_{k}\left(v_{j}\right)_{\mu}\right) d x d t \leq C \eta+\epsilon(n, j, \mu, m) .
\end{aligned}
$$

Proof of 777: Setting for $s>0, Q^{s}=\{(x, t) \in Q$ : $\left.\left|\nabla T_{k}(u)\right| \leq s\right\}$ and $Q_{j}^{s}=\left\{(x, t) \in Q:\left|\nabla T_{k}\left(v_{j}\right)\right| \leq s\right\}$ and denoting by $\chi^{s}$ and $\chi_{j}^{s}$ the characteristic functions of $Q^{s}$ and $Q_{j}^{s}$ respectively, we deduce that letting $0<\delta<1$, define

$$
\begin{gathered}
\Theta_{n, k}=\left(a\left(T_{k}\left(u_{n}\right), \nabla T_{k}\left(u_{n}\right)\right)-a\left(T_{k}\left(u_{n}\right), \nabla T_{k}(u)\right)\right) \\
\times\left(\nabla T_{k}\left(u_{n}\right)-\nabla T_{k}(u)\right)
\end{gathered}
$$

For $s>0$, we have

$0 \leq \int_{Q^{s}} \Theta_{n, k}^{\delta} d x d t=\int_{Q^{s}} \Theta_{n, k}^{\delta} \chi_{\left\{0 \leq T_{k}\left(u_{n}\right)-T_{k}\left(v_{j}\right)_{\mu} \leq \eta\right\}} d x d t$

$$
+\int_{Q^{s}} \Theta_{n, k}^{\delta} \chi_{\left\{T_{k}\left(u_{n}\right)-T_{k}\left(v_{j}\right)_{\mu}>\eta\right\}} d x d t
$$

The first term of the right-side hand, with the Hölder inequality,

$$
\begin{gathered}
\int_{Q^{s}} \Theta_{n, k}^{\delta} \chi_{\left\{0 \leq T_{k}\left(u_{n}\right)-T_{k}\left(v_{j}\right)_{\mu} \leq \eta\right\}} d x d t \leq \\
\left(\int_{Q^{s}} \Theta_{n, k} \chi_{\left\{0 \leq T_{k}\left(u_{n}\right)-T_{k}\left(v_{j}\right)_{\mu} \leq \eta\right\}} d x d t\right)^{\delta}\left(\int_{Q^{S}} d x d t\right)^{1-\delta} \\
\quad \leq C_{1}\left(\int_{Q^{s}} \Theta_{n, k} \chi_{\left\{0 \leq T_{k}\left(u_{n}\right)-T_{k}\left(v_{j}\right)_{\mu} \leq \eta\right\}} d x d t\right)^{\delta}
\end{gathered}
$$

Also using the Hölder inequality, the second term of the right-side hand is

$$
\begin{gathered}
\int_{Q^{s}} \Theta_{n, k}^{\delta} \chi_{\left\{T_{k}\left(u_{n}\right)-T_{k}\left(v_{j}\right)_{\mu} \eta\right\}} d x d t \leq\left(\int_{Q^{s}} \Theta_{n, k} d x d t\right)^{\delta} \\
\times\left(\int_{\left\{T_{k}\left(u_{n}\right)-T_{k}\left(v_{j}\right)_{\mu}>\eta\right\}} d x d t\right)^{1-\delta}
\end{gathered}
$$

since $a\left(x, t, T_{k}\left(u_{n}\right), \nabla T_{k}\left(u_{n}\right)\right)$ is bounded in $\left(L_{\bar{M}}\left(Q_{T}\right)\right)^{N}$, while $\nabla T_{k}\left(u_{n}\right)$ is bounded in $\left(L_{M}\left(Q_{T}\right)\right)^{N}$ then $\int_{Q^{s}} \Theta_{n, k}^{\delta} \chi_{\left\{T_{k}\left(u_{n}\right)-T_{k}\left(v_{j}\right)_{\mu} \eta\right\}} d x d t \leq C_{2}$ meas $\left\{(x, t) \in Q_{T}:\right.$ $\left.\left|T_{k}\left(u_{n}\right)-T_{k}\left(v_{j}\right)_{\mu}\right|>\eta\right\}^{1-\delta}$

We obtain,

$$
\int_{Q^{s}} \Theta_{n, k}^{\delta} d x d t \leq C_{1}\left(\int_{Q^{s}} \Theta_{n, k} \chi_{\left\{0 \leq T_{k}\left(u_{n}\right)-T_{k}\left(v_{j}\right)_{\mu} \leq \eta\right\}} d x d t\right)^{\delta}
$$

One easily has,

$\int_{\left.\{|u|>k\} \cap\left\{0 \leq T_{k}(u)-T_{k}(u)_{\mu}\right) \leq \eta\right\}} S_{m}(u) \exp (G(u)) \nabla T_{k}(u)_{\mu} \Phi_{k+\eta} d x d t$

$$
+C_{2} \text { meas }\left\{(x, t) \in Q_{T}: T_{k}\left(u_{n}\right)-T_{k}\left(v_{j}\right)_{\mu}>\eta\right\}^{1-\delta}
$$

On the other hand,

$$
=\epsilon(n, j, \mu) .
$$

By (70)-76), 79) and 80) we obtain

$$
\int_{Q^{s}} \Theta_{n, k} \chi_{\left\{0 \leq T_{k}\left(u_{n}\right)-T_{k}\left(v_{j}\right)_{\mu} \leq \eta\right\}} d x d t
$$

$$
\begin{array}{cc}
\int_{\left.\left\{\left|u_{n}\right| \leq k\right\} \cap\left\{0 \leq T_{k}\left(u_{n}\right)-T_{k}\left(v_{j}\right)_{\mu}\right) \leq \eta\right\}} a_{n}\left(T_{k}\left(u_{n}\right), \nabla T_{k}\left(u_{n}\right)\right) S_{m}\left(u_{n}\right) & \leq \int_{0 \leq T_{k}\left(u_{n}\right)-T_{k}\left(v_{j}\right)_{\mu} \leq \eta}\left(a\left(T_{k}\left(u_{n}\right), \nabla T_{k}\left(u_{n}\right)\right)\right. \\
\exp \left(G\left(u_{n}\right)\right)\left(\nabla T_{k}\left(u_{n}\right)-\nabla T_{k}\left(v_{j}\right)_{\mu}\right) d x d t & \left.-a\left(T_{k}\left(u_{n}\right), \nabla T_{k}(u) \chi_{s}\right)\right)\left(\nabla T_{k}\left(u_{n}\right)-\nabla T_{k}(u) \chi_{s}\right) d x d t
\end{array}
$$


For each $s>r, r>0$, one has

$$
\begin{aligned}
& 0 \leq \int_{Q^{r} \cap\left\{0 \leq T_{k}\left(u_{n}\right)-T_{k}\left(v_{j}\right)_{\mu} \leq \eta\right\}}\left(a\left(T_{k}\left(u_{n}\right), \nabla T_{k}\left(u_{n}\right)\right)\right. \\
& \left.-a\left(T_{k}\left(u_{n}\right), \nabla T_{k}(u)\right)\right)\left(\nabla T_{k}\left(u_{n}\right)-\nabla T_{k}(u)\right) d x d t \\
& \leq \int_{Q^{s} \cap\left\{0 \leq T_{k}\left(u_{n}\right)-T_{k}\left(v_{j}\right)_{\mu} \leq \eta\right\}}\left(a\left(T_{k}\left(u_{n}\right), \nabla T_{k}\left(u_{n}\right)\right)\right. \\
& \left.-a\left(T_{k}\left(u_{n}\right), \nabla T_{k}(u)\right)\right)\left(\nabla T_{k}\left(u_{n}\right)-\nabla T_{k}(u)\right) d x d t \\
& =\int_{Q^{s} \cap\left\{0 \leq T_{k}\left(u_{n}\right)-T_{k}\left(v_{j}\right)_{\mu} \leq \eta\right\}}\left(a\left(T_{k}\left(u_{n}\right), \nabla T_{k}\left(u_{n}\right)\right)\right. \\
& \left.-a\left(T_{k}\left(u_{n}\right), \nabla T_{k}(u) \chi_{s}\right)\right)\left(\nabla T_{k}\left(u_{n}\right)-\nabla T_{k}(u) \chi_{s}\right) d x d t \\
& \leq \int_{Q \cap\left\{0 \leq T_{k}\left(u_{n}\right)-T_{k}\left(v_{j}\right)_{\mu} \leq \eta\right\}}\left(a\left(T_{k}\left(u_{n}\right), \nabla T_{k}\left(u_{n}\right)\right)\right. \\
& \left.-a\left(T_{k}\left(u_{n}\right), \nabla T_{k}(u) \chi^{s}\right)\right)\left(\nabla T_{k}\left(u_{n}\right)-\nabla T_{k}(u) \chi^{s}\right) d x d t \\
& =\int_{\left\{0 \leq T_{k}\left(u_{n}\right)-T_{k}\left(v_{j}\right)_{\mu} \leq \eta\right\}}\left(a\left(T_{k}\left(u_{n}\right), \nabla T_{k}\left(u_{n}\right)\right)\right. \\
& \left.-a\left(T_{k}\left(u_{n}\right), \nabla T_{k}\left(v_{j}\right) \chi_{j}^{s}\right)\right)\left(\nabla T_{k}\left(u_{n}\right)-\nabla T_{k}\left(v_{j}\right) \chi_{j}^{s}\right) d x d t \\
& +\int_{\left\{0 \leq T_{k}\left(u_{n}\right)-T_{k}\left(v_{j}\right)_{\mu} \leq \eta\right\}} a\left(T_{k}\left(u_{n}\right), \nabla T_{k}\left(u_{n}\right)\right) \\
& \times\left(\nabla T_{k}\left(v_{j}\right) \chi_{j}^{s}-\nabla T_{k}(u) \chi^{s}\right) d x d t \\
& +\int_{\left\{0 \leq T_{k}\left(u_{n}\right)-T_{k}\left(v_{j}\right)_{\mu} \leq \eta\right\}}\left(a\left(T_{k}\left(u_{n}\right), \nabla T_{k}\left(v_{j}\right) \chi_{j}^{s}\right)\right. \\
& \left.-a\left(T_{k}\left(u_{n}\right), \nabla T_{k}(u) \chi^{s}\right)\right) \nabla T_{k}\left(u_{n}\right) d x d t \\
& -\int_{\left\{0 \leq T_{k}\left(u_{n}\right)-T_{k}\left(v_{j}\right)_{\mu} \leq \eta\right\}} a\left(T_{k}\left(u_{n}\right), \nabla T_{k}\left(v_{j}\right) \chi_{j}^{s}\right) \\
& \left.\times \nabla T_{k}\left(v_{j}\right) \chi_{j}^{s}\right) d x d t
\end{aligned}
$$$$
\left.+\int_{\left\{0 \leq T_{k}\left(u_{n}\right)-T_{k}\left(v_{j}\right)_{\mu} \leq \eta\right\}} a\left(T_{k}\left(u_{n}\right), \nabla T_{k}(u) \chi^{s}\right) \nabla T_{k}(u) \chi^{s}\right) d x d t
$$$$
=I_{1}(n, j, s)+I_{2}(n, j)+I_{3}(n, j)+I_{4}(n, j, \mu)+I_{5}(n, \mu)
$$

we will go to the limit as $\mathrm{n}, \mathrm{j}, \mu$, and $s \rightarrow+\infty I_{1}=$ $\int_{\left\{0 \leq T_{k}\left(u_{n}\right)-T_{k}\left(v_{j}\right)_{\mu} \leq \eta\right\}} a\left(T_{k}\left(u_{n}\right), \nabla T_{k}\left(u_{n}\right)\right)$

$$
\begin{array}{r}
\times\left(\nabla T_{k}\left(u_{n}\right)-\nabla T_{k}\left(v_{j}\right)_{\mu}\right) d x d t \\
-\int_{\left\{0 \leq T_{k}\left(u_{n}\right)-T_{k}\left(v_{j}\right)_{\mu} \leq \eta\right\}} a\left(T_{k}\left(u_{n}\right), \nabla T_{k}\left(u_{n}\right)\right) \\
\times\left(\nabla T_{k}\left(v_{j}\right) \chi_{j}^{s}-\nabla T_{k}\left(v_{j}\right)_{\mu}\right) d x d t \\
\left.-\int_{\left\{0 \leq T_{k}\left(u_{n}\right)-T_{k}\left(v_{j}\right)_{\mu} \leq \eta\right\}} a\left(T_{k}\left(u_{n}\right), \nabla T_{k}\left(v_{j}\right) \chi_{j}^{s}\right)\right) \\
\left.\times\left(\nabla T_{k}\left(u_{n}\right)-\nabla T_{k}\left(v_{j}\right) \chi_{j}^{s}\right)\right) d x d t
\end{array}
$$

Using [81, the first term of the right-hand side, we get $\int_{\left\{0 \leq T_{k}\left(u_{n}\right)-T_{k}\left(v_{j}\right)_{\mu} \leq \eta\right\}} a\left(T_{k}\left(u_{n}\right), \nabla T_{k}\left(u_{n}\right)\right)\left(\nabla T_{k}\left(u_{n}\right)-\right.$ $\left.\nabla T_{k}\left(v_{j}\right)_{\mu}\right) d x d t$

$$
\leq C \eta+\epsilon(n, m, j, s)
$$

$$
\begin{gathered}
-\int_{\{|u|>k\} \cap\left\{\left|T_{k}(u)-T_{k}\left(v_{j}\right)_{\mu}\right| \leq \eta\right\}} a\left(T_{k}(u), 0\right) \nabla T_{k}\left(v_{j}\right)_{\mu} d x d t \\
\leq C \eta+\epsilon(n, m, j, \mu)
\end{gathered}
$$

The second term of the right-hand side tends to

$$
\int_{\left\{\left|T_{k}(u)-T_{k}\left(v_{j}\right)_{\mu}\right| \leq \eta\right\}} \omega_{k}\left(\nabla T_{k}\left(v_{j}\right) \chi_{j}^{s}-\nabla T_{k}\left(v_{j}\right)_{\mu}\right) d x d t
$$

since $a\left(T_{k}\left(u_{n}\right), \nabla T_{k}\left(u_{n}\right)\right)$ is bounded in $\left(L_{\bar{M}}\left(Q_{T}\right)\right)^{N}$, there exist some $\omega_{k} \in\left(L_{\bar{M}}\left(Q_{T}\right)\right)^{N}$ such that (for a subsequence still denoted by $u_{n}$

$$
\begin{gathered}
a\left(T_{k}\left(u_{n}\right), \nabla T_{k}\left(u_{n}\right)\right) \rightarrow \omega_{k} \quad \text { in }\left(L_{M}\left(Q_{T}\right)\right)^{N} \\
\text { for } \sigma\left(\Pi L_{\bar{M}}, \Pi E_{M}\right)
\end{gathered}
$$

In view of the fact that

$\left(\nabla T_{k}\left(v_{j}\right) \chi_{j}^{s} \quad-\nabla T_{k}\left(v_{j}\right)_{\mu}\right) \chi_{\left\{0 \leq T_{k}\left(u_{n}\right)-T_{k}\left(v_{j}\right)_{\mu} \leq \eta\right\}} \rightarrow$ $\left(\nabla T_{k}\left(v_{j}\right) \chi_{j}^{s}-\nabla T_{k}\left(v_{j}\right)_{\mu}\right) \chi_{\left\{0 \leq T_{k}(u)-T_{k}\left(v_{j}\right)_{\mu} \leq \eta\right\}}$ Strongly in $\left(E_{M}\left(Q_{T}\right)\right)^{N}$ as $n \rightarrow+\infty$.

the third term of the right-hand side tends to

$\left.\int_{\left\{0 \leq T_{k}(u)-T_{k}\left(v_{j}\right)_{\mu} \leq \eta\right\}} a\left(T_{k}(u), \nabla T_{k}\left(v_{j}\right) \chi_{j}^{s}\right)\right)$

$$
\left.\left(\nabla T_{k}(u)-\nabla T_{k}\left(v_{j}\right) \chi_{j}^{s}\right)\right) d x d t
$$

Since $\left.\quad a\left(T_{k}\left(u_{n}\right), \nabla T_{k}\left(v_{j}\right) \chi_{j}^{s}\right)\right) \chi_{\left\{0 \leq T_{k}\left(u_{n}\right)-T_{k}\left(v_{j}\right)_{\mu} \leq \eta\right\}} \rightarrow$ $\left.a\left(T_{k}(u), \nabla T_{k}\left(v_{j}\right) \chi_{j}^{s}\right)\right) \chi_{\left|T_{k}(u)-T_{k}\left(v_{j}\right)_{\mu}\right| \leq \eta} \quad$ in $\quad\left(E_{\bar{M}}\left(Q_{T}\right)\right)^{N}$ while

$$
\left.\left.\left(\nabla T_{k}\left(u_{n}\right)-\nabla T_{k}\left(v_{j}\right) \chi_{j}^{s}\right)\right) \rightarrow\left(\nabla T_{k}(u)-\nabla T_{k}\left(v_{j}\right) \chi_{j}^{s}\right)\right)
$$

in $\left(L_{M}\left(Q_{T}\right)\right)^{N}$ for $\sigma\left(\Pi L_{\bar{M}}, \Pi E_{M}\right)$ Passing to limit as $j \rightarrow+\infty$ and $\mu \rightarrow+\infty$ and using Lebesgue's theorem, we have

$$
I_{1} \leq C \eta+\epsilon(n, j, s, \mu)
$$

For what concerns $I_{2}$, by letting $n \rightarrow+\infty$, we have

$$
I_{2} \rightarrow \int_{\left\{0 \leq T_{k}(u)-T_{k}\left(v_{j}\right)_{\mu} \leq \eta\right\}} \omega_{k}\left(\nabla T_{k}\left(v_{j}\right) \chi_{j}^{s}-\nabla T_{k}(u) \chi^{s}\right) d x d t
$$

Since $a\left(T_{k}\left(u_{n}\right), \nabla T_{k}\left(u_{n}\right)\right) \rightarrow \omega_{k}$ in $\left(L_{\bar{M}}\left(Q_{T}\right)\right)^{N}$, for $\sigma\left(\Pi L_{\bar{M}}, \Pi E_{M}\right)$, while $\left(\nabla T_{k}\left(v_{j}\right) \chi_{j}^{s}-\nabla T_{k}(u) \chi^{s}\right) \chi_{\left\{0 \leq T_{k}\left(u_{n}\right)-T_{k}\left(v_{j}\right)_{\mu} \leq \eta\right\}}$

$$
\rightarrow\left(\nabla T_{k}\left(v_{j}\right) \chi_{j}^{s}-\nabla T_{k}(u) \chi^{s}\right) \chi_{\left\{0 \leq T_{k}(u)-T_{k}\left(v_{j}\right)_{\mu} \mid \leq \eta\right\}}
$$

strongly in $\left(E_{M}\left(Q_{T}\right)\right)^{N}$.

Passing to limit $j \rightarrow+\infty$, and using Lebesgue's theorem, we have

$$
I_{2}=\epsilon(n, j)
$$

Similar ways as above give

$$
I_{3}=\epsilon(n, j)
$$

$$
I_{4}=\int_{\left\{0 \leq T_{k}(u)-T_{k}(u)_{\mu} \leq \eta\right\}} a\left(T_{k}(u), \nabla T_{k}(u)\right) \nabla T_{k}(u) d x d t
$$

$$
+\epsilon(n, j, \mu, s, m)
$$




$$
\begin{gathered}
I_{5}=\int_{\left\{0 \leq T_{k}(u)-T_{k}(u)_{\mu} \leq \eta\right\}} a\left(T_{k}(u), \nabla T_{k}(u)\right) \nabla T_{k}(u) d x d t \\
+\epsilon(n, j, \mu, s, m)
\end{gathered}
$$

Finally, we obtain,

$\int_{Q^{s}} \Theta_{n, k} d x d t \leq C_{1}(C \eta+\epsilon(n, \mu, \eta, m))^{\delta}+C_{2}(\epsilon(n, \mu,))^{1-\delta}$

Which yields, by passing to the limit sup over $n, j, \mu, s$ and $\eta$
Since $\rho \in L^{1}(\mathbb{R})$, we get

$$
\lim _{h \rightarrow 0} \sup _{n \in \mathbb{N}} \int_{\left\{u_{n}>h\right\}} \rho\left(u_{n}\right) M\left(x, \nabla u_{n}\right) d x d t=0
$$

Similarly, let $g_{0}\left(u_{n}\right)=\int_{u_{n}}^{0} \rho(s) \chi_{\{s<-h\}} d x$ in 26, we have also

$$
\lim _{h \rightarrow 0} \sup _{n \in \mathbb{N}} \int_{\left\{u_{n}<-h\right\}} \rho\left(u_{n}\right) M\left(x, \nabla u_{n}\right) d x d t=0
$$

$\int_{Q^{r} \cap\left\{0 \leq T_{\eta}\left(T_{k}(u)-T_{k}(u)_{\mu}\right)\right\}}\left[\left(a\left(T_{k}\left(u_{n}\right), \nabla T_{k}\left(u_{n}\right)\right)-a\left(T_{k}\left(u_{n}\right), \nabla T_{k}(u) y e\right.\right.\right.$ conclude that

$$
\left.\left(\nabla T_{k}\left(u_{n}\right)-\nabla T_{k}(u)\right)\right]^{\delta} d x d t=\epsilon(n)
$$

$$
\lim _{h \rightarrow 0} \sup _{n \in \mathbb{N}} \int_{\left\{\left|u_{n}\right|>h\right\}} \rho\left(u_{n}\right) M\left(x, \nabla u_{n}\right) d x d t=0
$$

Taking on the hand the function $W_{\eta, \mu}^{n, j}=T_{\eta}\left(T_{k}\left(u_{n}\right)-\right.$ Let $D \subset Q_{T}$ then

$\left.\left(T_{k}\left(v_{j}\right)\right)_{\mu}\right)^{-}$and $W_{\eta, \mu}^{j}=T_{\eta}\left(T_{k}(u)-\left(T_{k}\left(v_{j}\right)\right)_{\mu}\right)^{-}$.
Multiplying the approximating equation by $\int_{D} \rho\left(u_{n}\right) M\left(x, \nabla u_{n}\right) d x d t \leq \max _{\left\{\left|u_{n}\right| \leq h\right\}} \rho(y) \int_{D \cap\left\{\left|u_{n}\right| \leq h\right\}} M\left(x, \nabla u_{n}\right) d x d t$ $\left.\exp \left(G\left(u_{n}\right)\right)\right) W_{\eta, \mu}^{n, j} S_{m}\left(u_{n}\right)$, we obtain

$$
\begin{gathered}
\int_{Q^{r} \cap\left\{T_{\eta}\left(T_{k}\left(u_{n}\right)-\left(T_{k}\left(v_{j}\right)\right)_{\mu}\right) \leq 0\right\}}\left[\left(a\left(x, T_{k}\left(u_{n}\right), \nabla T_{k}\left(u_{n}\right)\right)\right.\right. \\
\left.\left.-a\left(x, T_{k}\left(u_{n}\right), \nabla T_{k}(u)\right)\right)\left(\nabla T_{k}\left(u_{n}\right)-\nabla T_{k}(u)\right)\right]^{\delta} d x d t=\epsilon(n)
\end{gathered}
$$

by 82 and 83 we get

$$
\begin{gathered}
\int_{Q^{r}}\left[\left(a\left(x, T_{k}\left(u_{n}\right), \nabla T_{k}\left(u_{n}\right)\right)-a\left(x, T_{k}\left(u_{n}\right), \nabla T_{k}(u)\right)\right)\right. \\
\left.\times\left(\nabla T_{k}\left(u_{n}\right)-\nabla T_{k}(u)\right)\right]^{\delta} d x d t=\epsilon(n)
\end{gathered}
$$$$
+\int_{D \cap\left\{\left|u_{n}\right|>h\right\}} \rho\left(u_{n}\right) M\left(x, \nabla u_{n}\right) d x d t
$$

Consequently $\rho\left(u_{n}\right) M\left(x, \nabla u_{n}\right)$ is equi-integrable. Then $\rho\left(u_{n}\right) M\left(x, \nabla u_{n}\right)$ converge to $\rho(u) M(x, \nabla u)$ strongly in $L^{1}(I R)$. By 16 , we get our result.

As a conclusion, the proof of Theorem (4) is complete.

\section{References}

Thus, passing to a subsequence if necessary, $\nabla u_{n} \rightarrow$ $\nabla u$ a.e. in $Q^{r}$, and since $r$ is arbitrary,

$$
\nabla u_{n} \rightarrow \nabla u \quad \text { a.e. in } \quad Q_{T}
$$

Step 4: Equi-integrability of the nonlinearity sequence

We shall prove that $H_{n}\left(u_{n}, \nabla u_{n}\right) \rightarrow H(u, \nabla u)$ strongly in $L^{1}\left(Q_{T}\right)$.

Consider $g_{0}\left(u_{n}\right)=\int_{0}^{u_{n}} \rho(s) \chi_{\{s>h\}} d s$ and multiply 26 by $\exp \left(G\left(u_{n}\right)\right) g_{0}\left(u_{n}\right)$, we get

$$
\begin{aligned}
{\left[\int_{Q_{T}} B_{h}^{n}\left(x, u_{n}\right) d x\right]_{0}^{T}+\int_{Q_{T}} a\left(, u_{n}, \nabla u_{n}\right) \nabla\left(\exp \left(G\left(u_{n}\right)\right) g_{0}\left(u_{n}\right)\right) d x d t } \\
\quad+\int_{Q_{T}} \Phi_{n}\left(u_{n}, \nabla u_{n}\right) \nabla\left(\exp \left(G\left(u_{n}\right)\right) g_{0}\left(u_{n}\right)\right) d x d t \\
\left.\quad+\int_{Q_{T}} H_{n}\left(u_{n}, \nabla u_{n}\right) \exp \left(G\left(u_{n}\right)\right) g_{0}\left(u_{n}\right)\right) d x d t
\end{aligned}
$$$$
\leq\left(\int_{h}^{+\infty} \rho(s) d x\right) \exp \left(\frac{\|\rho\|_{L^{1}(R)}}{\alpha^{\prime}}\right)\left[\left\|f_{n}\right\|_{L^{1}(Q)}+\| h\left(x, t \|_{L^{1}\left(Q_{T}\right)}\right]\right.
$$

where $B_{h}^{n}(x, r)=\int_{0}^{r} \frac{\partial b(x, s)}{\partial s} g_{0}(s) \exp \left(G\left(T_{k}(s)\right)\right) d s \geq 0$ then using same technique in step 2 we can have

$$
\int_{\left\{u_{n}>h\right\}} \rho\left(u_{n}\right) M\left(x, \nabla u_{n}\right) d x d t \leq C\left(\int_{h}^{+\infty} \rho(s) d x\right)
$$

1. M. M. Porzio, " Existence of solutions for some noncoercive parabolic equations.", Discrete and Continuous Dynamical Systems. 5.3, 553-568, 1999.

2. L. Boccardo, L. Orsina, A. Porretta, " Some noncoercive parabolic equations with a lower order terms in divergence form.", Journal of Evolution Equations 3.3 Dedicated to philippe Bénilan, 407-418,2003.

3. R. Di Nardo, F. Feo, O. Guibé, " Existence result for nonlinear parabolic equations with lower order terms.", Analysis and Applications, Vol. 9, No. 2, 161186, 2011.

4. A. Aberqi, J. Bennouna, M. Mekkour, H. Redwane, "Nonlinear parabolic inequality with lower order terms.”, Applicable Analysis 2016.

5. L. Boccardo, " Dirichlet problems with singular convection terms and applications.", Journal of Differential Equations $258,2290-2314,2015$.

6. L. Boccardo, G. R. Cirmi, “ $W_{0}^{1,1}$ solutions of some unilateral problems.", Nonlinear Analysis Series A: Theorie, Methods and Applications, 121, 447-457, 2015.

7. G. Zecca, "Existence and uniqueness for nonlinear elliptic equations with lower order terms.", Nonlinear Analysis Serie A: Theorie, Methos and Applications, 75, 899-912, 2012.

8. Y. Akdim, J. Bennouna, M. Mekkour, H. Redwane, " Strongly nonlinear parabolic inequality in Orlicz spaces via a sequence of penalized equations.", African Mathematical Union 2014.

9. M. Mabdaoui, H. Moussa, M. Rhoudaf, " Entropy solutions for a nonlinear parabolic problems with lower order term in Orlicz spaces.",Analysis and Mathematical Physics DOI 10.1007/s13324-016-0129-5, 2016. 
10. J. Musielak, "Modular spaces and Orlicz spaces.", Lecture Notes in Math, 1983.

11. A. Ahmed, A. Benkirane, M.S.B.Elemine Vall, A. Touzani, “ Existence of entropy solutions for nonlinear elliptic equations in Musielak framework with $L^{1}$ data.", Boletim da Sociedade Paranaense de Matematica (3s.) v. $361:$ 125150, 2018.

12. A. Benkirane, M. Sidi El Vally, "Some approximation properties in Musielak-Orlicz-Sobolev spaces." , Thai Journal of Mathematics, pp. 371-381, 2012.

13. A. Benkirane, M. Sidi El Vally, "Variational inequalities in Musielak-Orlicz-Sobolev spaces." , Bulletin of the Belgian Mathematical Society, pp. 787-811, 2014.

14. M.L. Ahmed Oubeid , A. Benkirane, M. Sidi El Vally, “ Strongly nonlinear parabolic problems in Musiealak-OrliczSobolev spaces.", Boletim da Sociedade Paranaense de Matematica, v. (33) 1 , 193-225,2015.

15. M. Ait Kellou, A. Benkirane, S.M. Douiri, “ An inequality of type Poincare in Musielak spaces and applications to some nonlinear elliptic problems with $L^{1}$-data." ,Complex Variables and Elliptic Equations 60, pp. 1217-1242, 2015.

16. H. Redwane, "Existence of a solution for a class of nonlinear parabolic systems. ", Electronic Journal of Qualitative Theory of Differential Equations 24, 18pp., 2007.
17. A. Benkirane, J. Bennouna, " Existence of entropy solutions for some nonlinear problems in orlicz spaces.", Nonlinear Analysis 54, 85-102, 2001.

18. R. Adams, "Sobolev spaces.",New York (NY):Academic Press, 1975.

19. H. Brezis, " Analyse fonctionnelle.", Masson, 1987.

20. R. Landes, "On the existence of weak solutions for quasilinear parabolic initial-boundary value problems.", Proceedings of the Royal Society of Edinburgh Section A 89, 217-237, 1981.

21. Y. Akdim, N. El gorch, M. Mekkour, " Existence of renormalized solutions for $\mathrm{p}(\mathrm{x})$-parabolic equations with three unbounded non- linearities.", Boletim da Sociedade Paranaense de Matematica, v (3) 34 , no. 1, 225-252, 2016.

22. D. Blanchard, H. Redwane, " Renormalized solutions for class of nonlinear evolution problems.", Journal de Mathmatiques Pures et Appliques. 77, pp. 117-151, 1998.

23. M.S.B. Elemine Vall, A. Ahmed, A. Touzani, A. Benkirane, " Existence of entropy solutions for nonlinear elliptic equations in Musielak framework with L1 data.", Boletim da Sociedade Paranaense de Matematica, v (3s.) v. 36 1, 125150, 2018. 